\title{
Relevance of the IIHS Small Overlap Crash Test in Europe
}

\author{
Raphael Murri", Sandro Caviezel \\ DTC Dynamic Test Center AG \\ *Corresponding Author: raphael.murri@bfh.ch
}

Copyright (C) 2014 Horizon Research Publishing All rights reserved.

\begin{abstract}
Modern cars often perform poorly in the new small overlap crash test of the Insurance Institute for Highway Safety (IIHS). This frontal impact replicates what happens, when only the front corner of the vehicle collides with another vehicle or an object such as a pillar or a tree. European vehicle manufacturers criticise that the IIHS small overlap crash test would not be relevant based on accident statistics and that two-way traffic collisions could not be reproduced with a rigid barrier. The DTC Dynamic Test Center AG in Switzerland did research on the relevance of the IIHS small overlap crash test in Europe. Therefore the reproducibility of the IIHS barrier in comparison with real two-way traffic collisions was examined. Three tests were performed with a randomly chosen Renault Scénic II using different test configurations. In a fourth test was the influence of the vehicle slip off from the barrier analysed implemented by design modifications on the test vehicle. Loads of the anthropomorphic test device (ATD) placed on the driving seat were measured during each test to draw conclusions on biomechanical stress and occupant protection. The results obtained show that a collision of real two-way traffic collision can be reproduced on a rigid barrier if the impact velocity is adapted on the involved vehicles. If a car is not designed for the IIHS small overlap crash test, speed reduction by main absorbing elements could be marginal and therefore significantly increase the biomechanical stress on the occupant. It has been shown that the vehicle slip off from the barrier could decrease the biomechanical stress but requires a frontal-/ side impact adapted restraint system. The front wheel must be prevented from penetrating the occupant foot well. To avoid injury risks of likely secondary collision further measures such as multifunctional airbags with sufficient residual energy should be taken. With regard to the analysed tests the conclusion was drawn that a slip off from the barrier in combination with necessary adaptions could decrease the injury risk. It can be concluded that the IIHS small overlap crash test is relevant for Europe due to the identified key gaps for occupant protection.
\end{abstract}

Keywords Relevance of the IIHS Small Overlap Crash Test, IIHS Small Overlap, IIHS Small Overlap Crash In Comparison to the Two-way Traffic Collision, Two-way
Traffic Collision, IHS Small Overlap Crash Test Modified Vehicle, IIHS Small Overlap Crash with Reduced Velocity, IIHS Small Overlap Crash Slip Off, Dynamic Test Center AG

\section{Introduction}

With support from Renault, the Baloise Insurance and the AGU Working Group on Accident Mechanics the DTC Dynamic Test Center AG of Switzerland researched the relevance of the IIHS small overlap crash tests in Europe. The crash investigation will show whether and how well a two-way traffic collision can be reproduced on the rigid IIHS barrier and with which challenges the vehicle manufacturers are faced by the IIHS small overlap crash test. The randomly chosen Renault Scénic II was used as test vehicle.

\section{Relevance Regarding Real Accident}

The Baloise Insurance analysed relating to the research their accidents internally regarding the overlap. It has been shown that every 5 th frontal accident occurs with small overlap in Switzerland (Fig 1 and 2).[1] The consequences are dramatic regarding occupant injury due to strong deformation of the passenger compartment. Accident reports were picked up by chance in December 2012. The vehicle deformations were very close to the tested vehicles on the rigid IIHS barrier.

The longitudinal bars of the vehicles are ineffective due to the small overlap. The front wheel is separated from the suspension and pressed into the foot well (Fig 1 and 2). Thereby only very little energy can be reduced. The passenger compartment collapses if cars cannot slip off sufficiently due to the blocking.

The statistics of the Baloise Insurance as well as the accident images clearly show that the IIHS small overlap crash test shows a gap in the safety concept of present vehicles. 


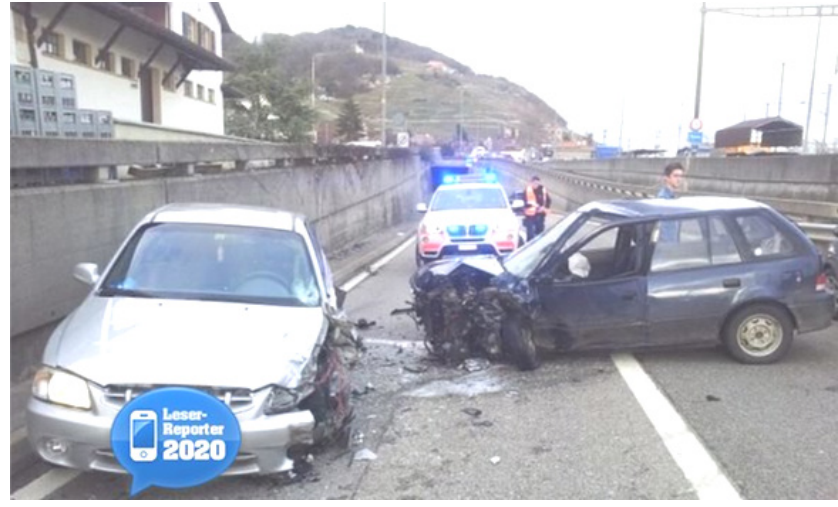

Figure 1. Accident A5 Twann [2]
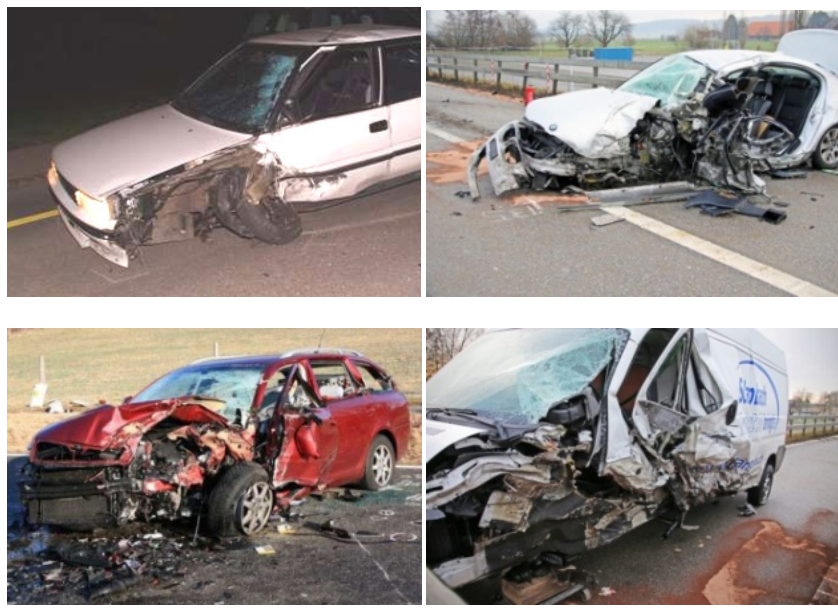

Figure 2. Pictures of really crashed cars in Dezember 2012 [2]

\section{Test configurations}

Within the DTC investigations on the IIHS small overlap four crash tests were conducted.

The specifications of the IIHS were applied for the small overlap crash test (Fig. 3). [3]

- $\quad 25 \%$ overlap to a rigid barrier

- $\quad$ Impact velocity $64.4+/-1 \mathrm{~km} / \mathrm{h}$

- $\quad$ ATD HIII $50 \%$ on driving seat

Differing from the IIHS requirements the parking brake was not applied after any test.

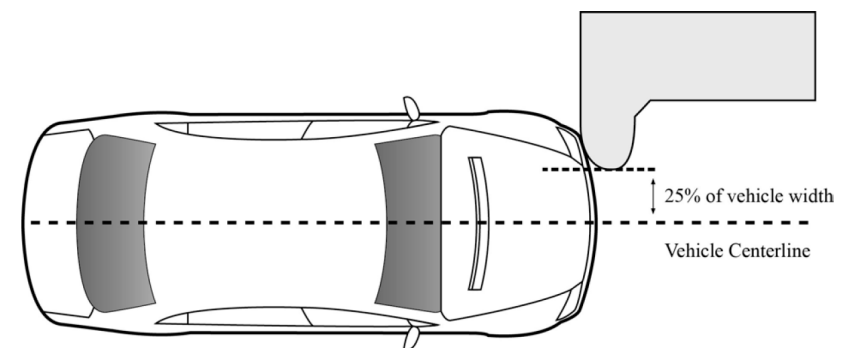

Figure 3. Vehicel at the rigid IIHS Barrier [6]
The first crash test DTC 150 (Fig. 4) with a Renault Scénic II was performed according to the IIHS standards. The aim of the test was to study the behaviour of the selected vehicle and to obtain basis of comparison for a two-way traffic collision between two vehicles (DTC 151).

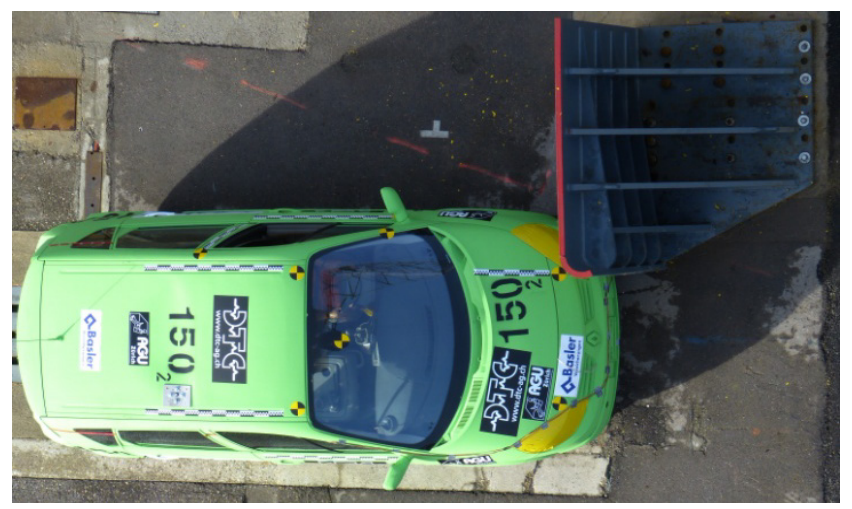

Figure 4. Renault Scénic II at the rigid IIHS Barrier

\subsection{DTC 151 Two-way Traffic Collision}

A two-way traffic collision between a Renault Scénic II and a Land Rover Freelander (Fig. 5) was examined. The focus was on how well the structure and occupant loads on the Renault Scénic can be depict by the IIHS small overlap crash test against a real accident. It could be determined that the impact should be conducted with at least $100 \mathrm{~km} / \mathrm{h}$ relative velocity by using simulations of the accident analysis.

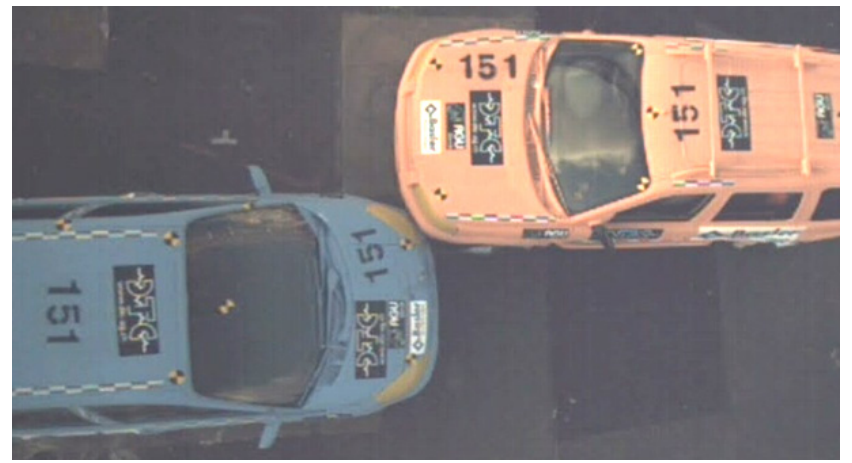

Figure 5. Renault Scénic II against Landrover Freelander

This simulation has also shown that the two vehicles will slip off each other. Therefore, the energy input into the vehicle structure cannot be substantially enhanced by increasing the impact speed of the Renault Scénic II. The crash test was performed with $104.8 \mathrm{~km} / \mathrm{h}$ speed and an overlap of $25 \%$ against a stationary Land Rover Freelander. The Land Rover Freelander was loaded on his gross vehicle weight with mass dummies and additional weight.

\subsection{DTC 149 Renault Scénic, IIHS with Reduced Velocity}

Despite the high relative speed of $104.8 \mathrm{~km} / \mathrm{h}$ the 
vehicles slipped off each other at the two-way traffic collision. Because the damage severity with the chosen vehicle pairing at the two-way traffic collision turned out to be less severe than expected the third crash test, DTC 149 (Fig. 6), examines the damage severity on the Scénic II at reduced speed against the IIHS barrier. At the Renault Scénic II was a collision-induced velocity change of about $40 \mathrm{~km} / \mathrm{h}$ detected.

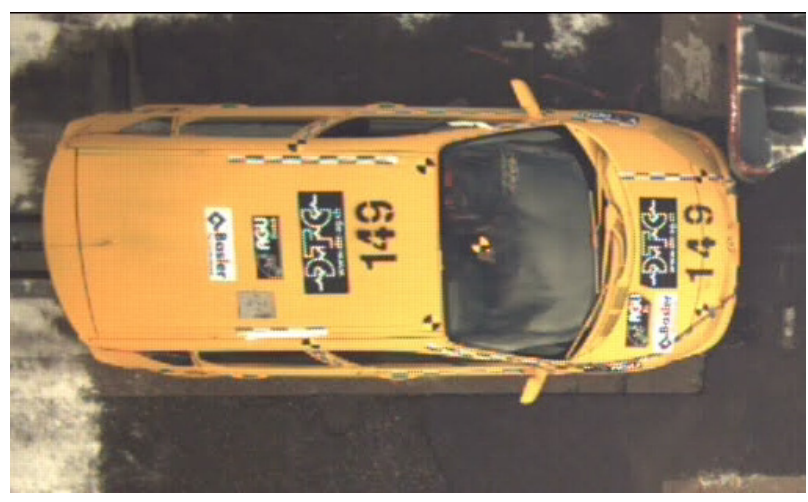

Figure 6. Renault Scénic II at the IIHS barrier

The impact velocity of the crash test DTC 149 has been reduced to $46 \mathrm{~km} / \mathrm{h}$ to initiate at the rigid IIHS barrier a similar energy absorption in the front structure. This reduction only applies to the tested vehicle pairing Renault Scénic II - Land Rover Freelander. For other vehicles the corresponding impact velocity against the IIHS small overlap barrier can change depending on the body structure, vehicle mass, the stability of the passenger compartment and the longitudinal bar position.

\subsection{DTC 152 Ford Mondeo Modified, According to IIHS}

At the example of a modified Ford Mondeo the approach of a slip off was examined (Fig. 7). Therefore the vehicle had been modified with steel profiles (Fig. 8) so that it slips off from the IIHS small overlap barrier and that the left front wheel is pushed inward before the passenger compartment impacts on the IIHS small overlap barrier.

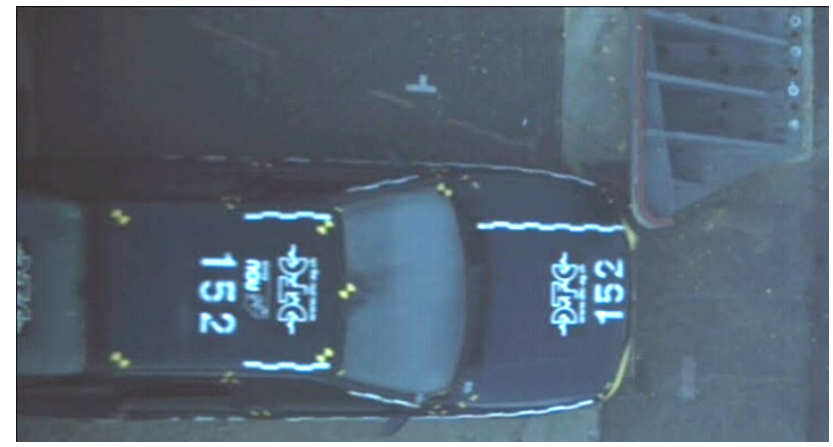

Figure 7. Modified Ford Mondeo at the IIHS barrier

The modifications (Fig. 8) only serve to force the vehicle slipping off the rigid barrier. These implemented interventions in the front structure are not practicable in the present version. But they represent the two needed measures to achieve a slipping in the IIHS small overlap crash test. The vehicle has been modified with various steel sections so that by the impact on the IIHS small overlap barrier a hooking can be avoided and that the wheel is pressed inward before the passenger compartment hits the IIHS small overlap barrier.

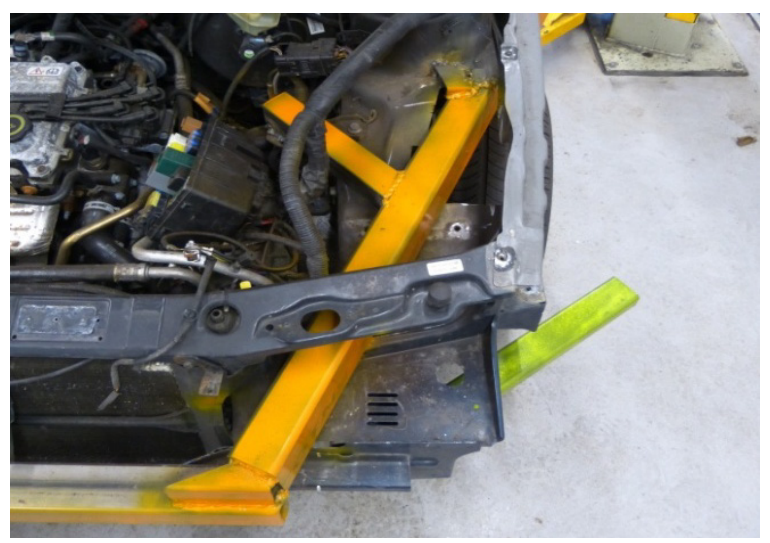

Figure 8. Vehicel structure at the impact area

This crash test and the variant chosen should show the necessary modifications so that the car can slip off from the IIHS barrier. The primary concern is the effect of these measures on the occupant load. It should however also demonstrate what movement of the vehicle after the primary impact is to be expected. It should be noted that the vehicle was not designed for the Euro-NCAP due to the model age and the equipped airbags.

Pre-tests with similar vehicle models (Fig. 9, 10 and 11) have shown that the cabins of this generation have a strong tendency to collapse in the IIHS small overlap crash test with $64 \mathrm{~km} / \mathrm{h}$.

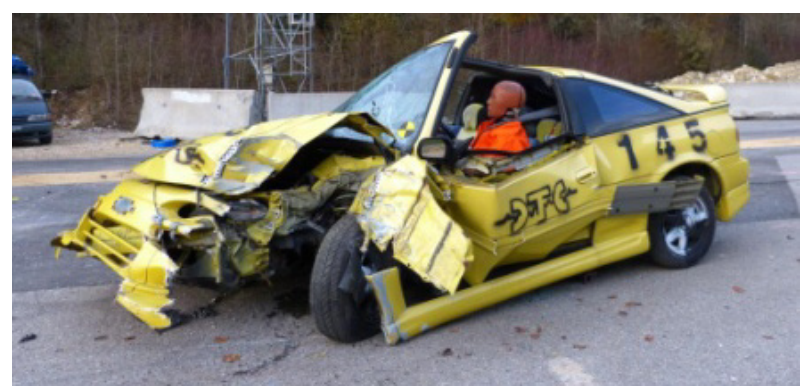

Figure 9. DTC 145 Nissan $100 \mathrm{NX}$

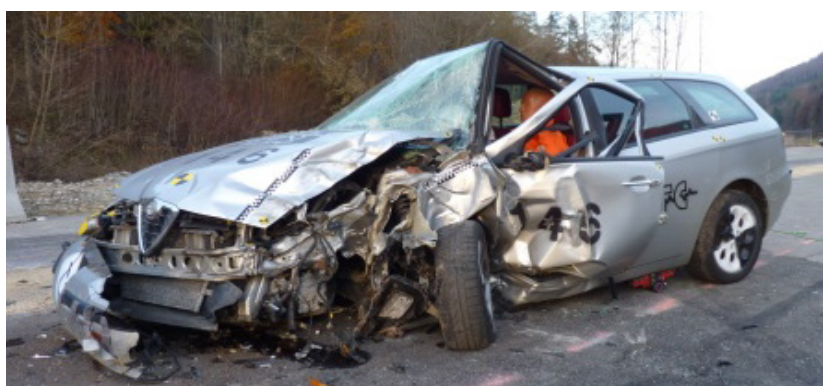

Figure 10. DTC 146 Alfa Romeo 156 


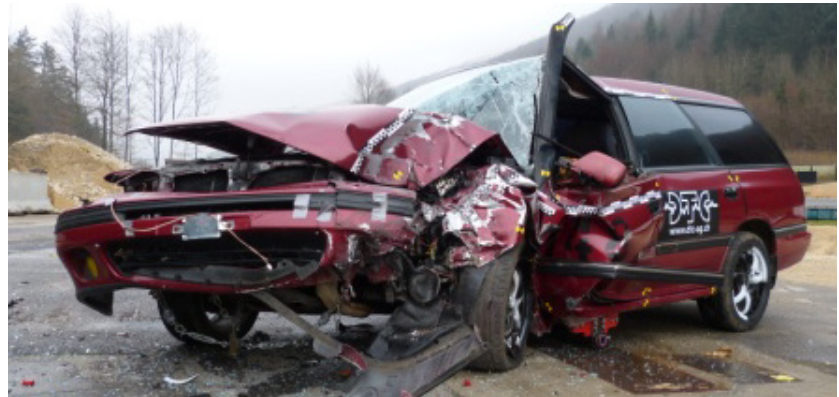

Figure 11. DTC 148 Subaru Legacy

\section{Results}

\subsection{DTC 150 Renault Scénic II, According to IIHS}

The vehicle hits the IIHS small overlap barrier with 65.2 $\mathrm{km} / \mathrm{h}$ and an overlap of $25 \%$. The Renault Scénic II grazed with the left longitudinal bar along the barrier and reduced only slightly energy (Fig. 12). Also the left front wheel was torn off and pushed back against the foot well. The passenger compartment and the IIHS small overlap barrier finally form one block. The car did not slip off and came almost to a standstill on the barrier. The vehicle started to rotate around the z-axis.

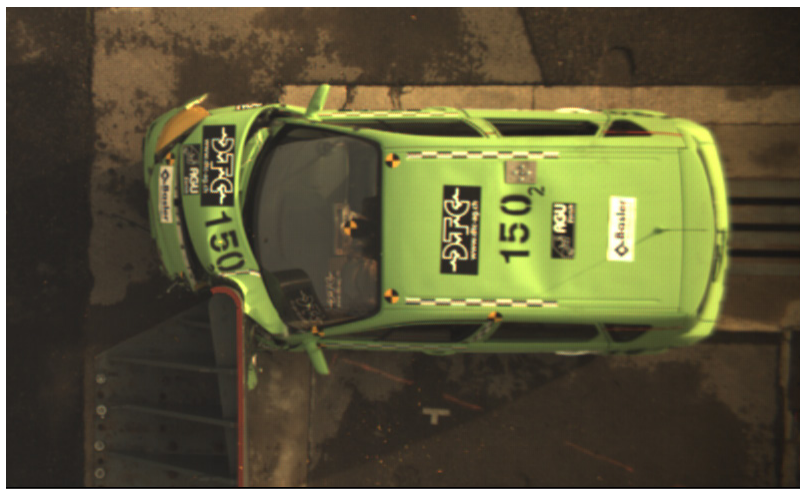

Figure 12. The left longitudinal bar doesn't hit the barrier

The passenger compartment collapsed due to the hard impact (Fig. 13). The foot well of the driver was severely deformed because the left front wheel was pushed into it. As a result increased loads were measured in the legs of the driver ATD. The passenger compartment deformed in such an extent that the dashboard on the left, the steering column and the steering wheel had been pressed into the interior. The restraint systems such as airbags and belt tensioners were triggered.

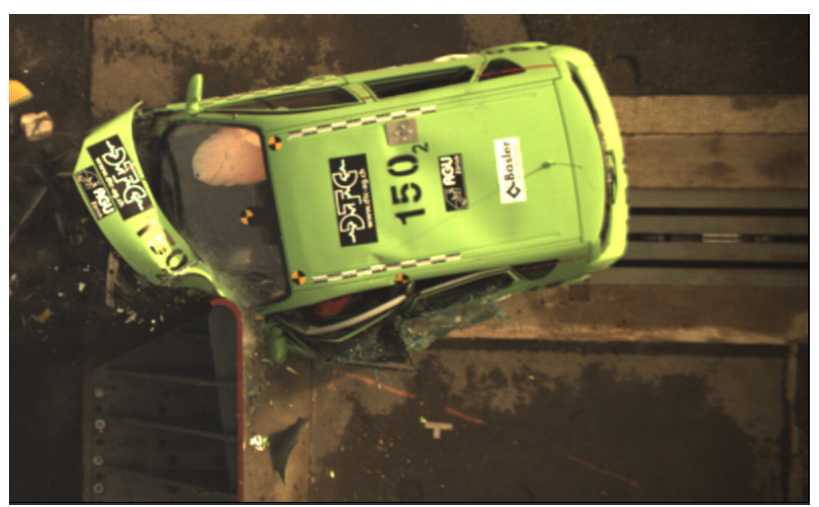

Figure 13. The passenger compartment collapses

The acceleration during the first $40 \mathrm{~ms}$ is on a low level (Fig. 14), compared with the impact after that to the vehicle compartment.

During the complete impact duration a strong rotation takes place (Fig. 15).

A very high injury risk must be expected on the lower extremities for the occupant on the driving seat (Fig. 16). The ATD head still hits the front airbag despite the rotative movement of the vehicle, the resulting direction of movement of the driver ATD and the displacement of the steering column, (Fig. 18). The restraint systems such as seat belts, belt tensioners and airbags developed their protective effects.

The compressive loads on the right femur resulted higher due to the lateral displacement of the dashboard pushing the right knee of the dummy into the steering column (Fig. 17). The biomechanical limits according to ECE-R 94 (frontal crash) were not exceeded on the ATD. [4] 


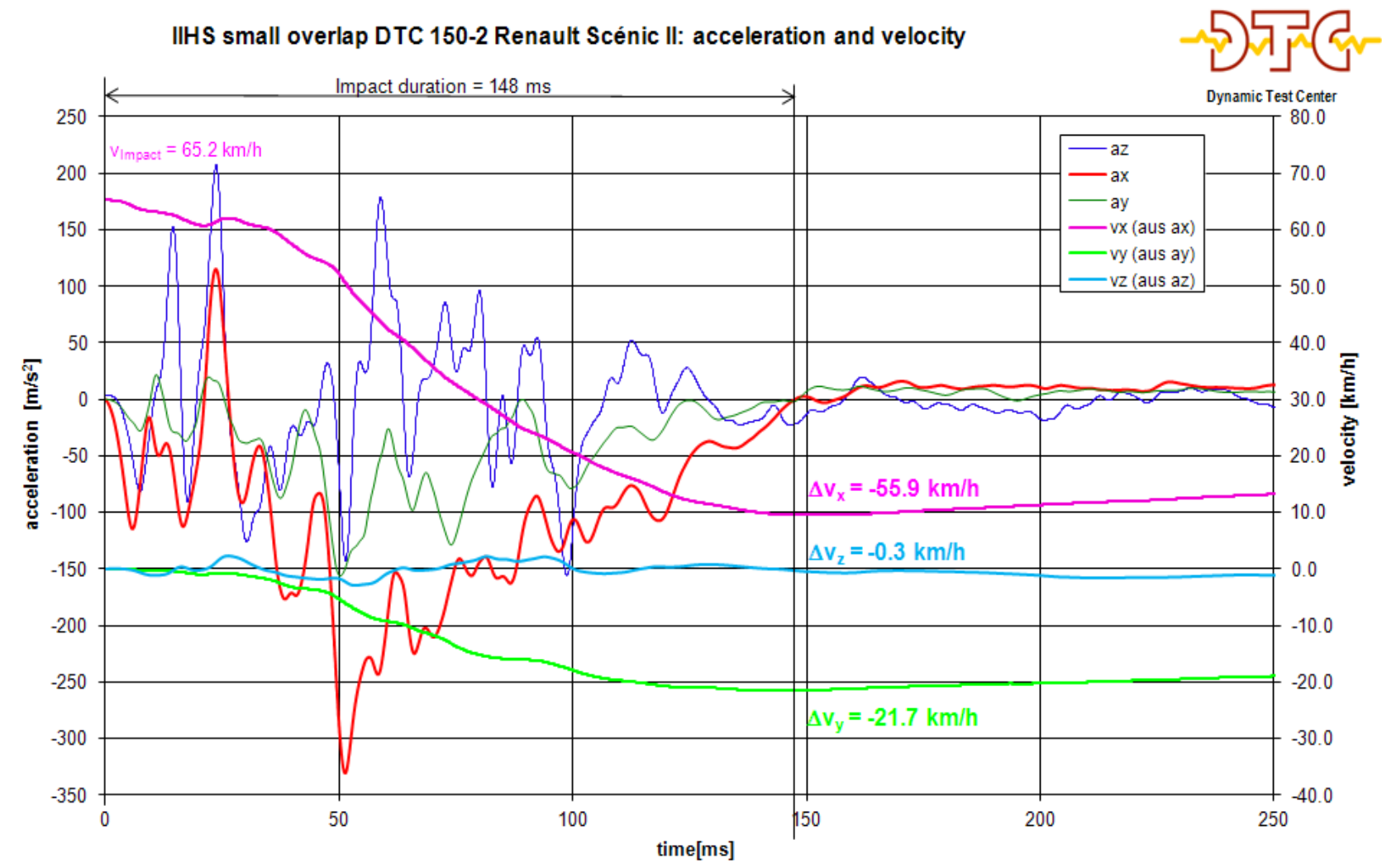

Figure 14. Vehicle loads

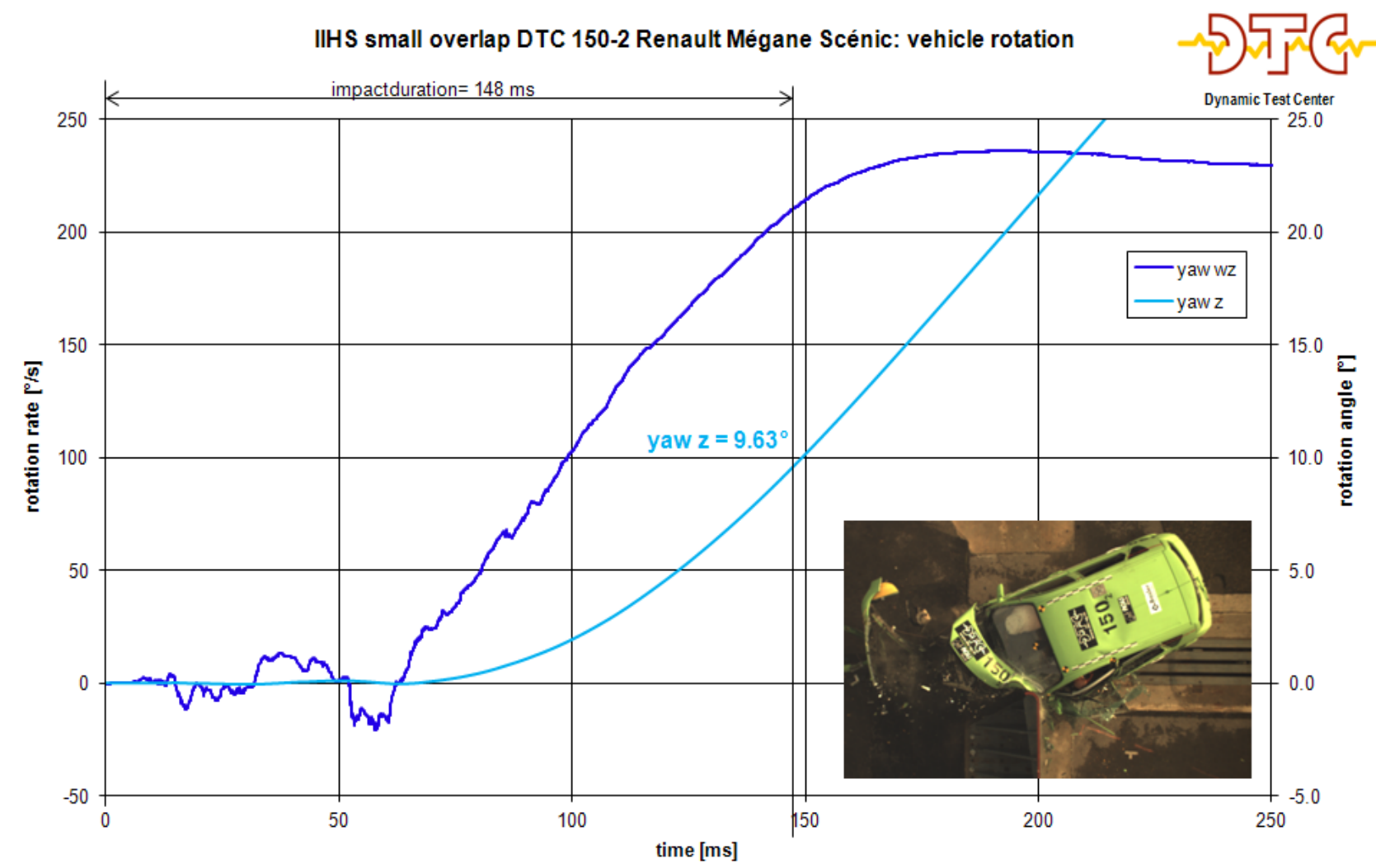

Figure 15. Vehicle rotation 


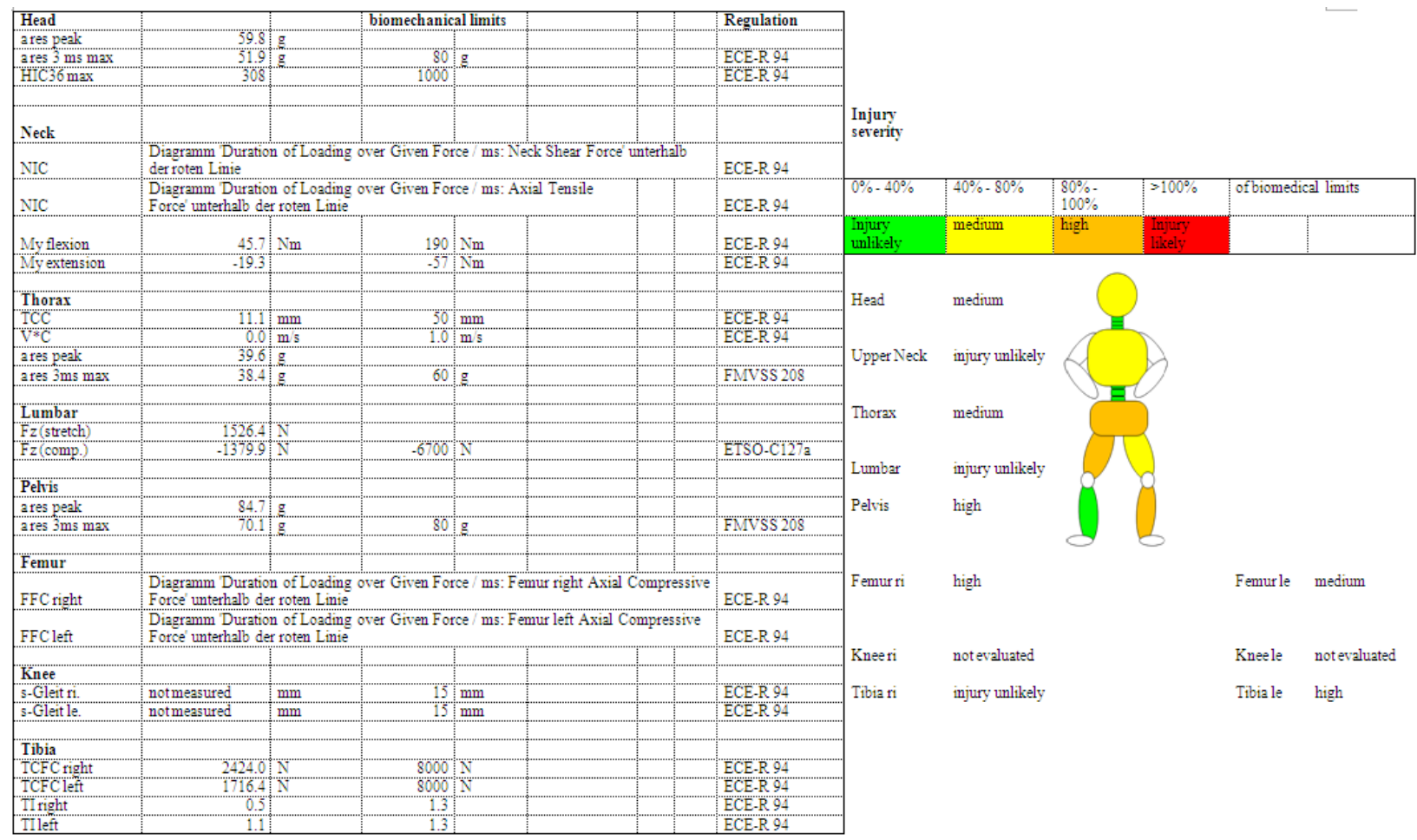

Figure 16. Loads on driver ATD

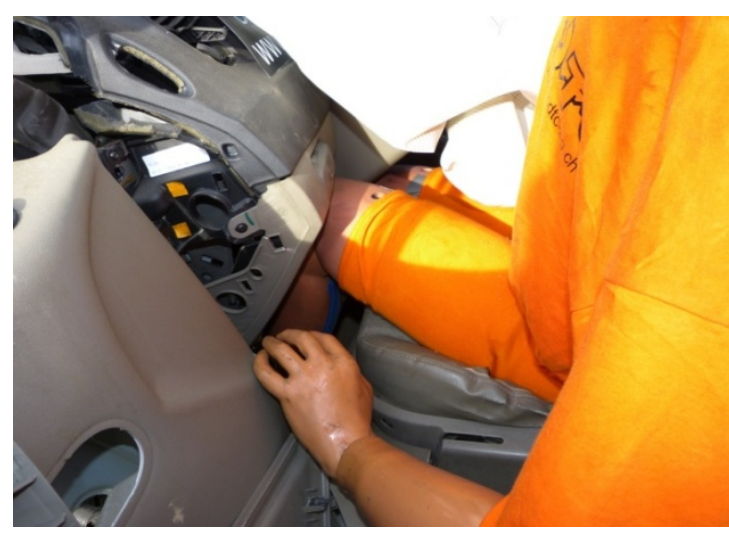

Figure 17. Reduced driver foot well

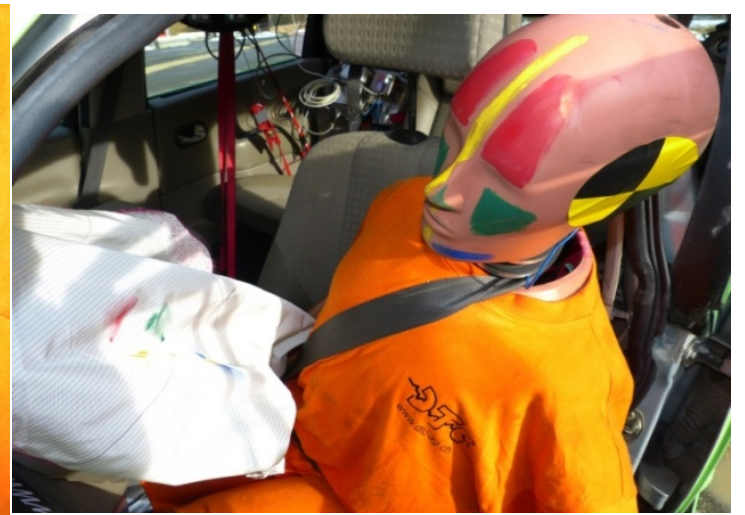

Figure 18. Marks of the dummy head on the airbag

\subsection{DTC 151 Two-way Traffic Collision Renault ScÉNic II - Landrover Freelander}

The Renault Scénic II hits the stationary Land Rover Freelander with $104.8 \mathrm{~km} / \mathrm{h}$ and an overlap of 25\%. The Renault Scénic II slipped with its left longitudinal bar, far away from the longitudinal bar of the Land Rover Freelander, only through soft structural body parts (Fig. 19). The wheels provided with their suspensions some resistance. Nevertheless, the longitudinal deceleration during the first $32 \mathrm{~ms}$ were on average $4.8 \mathrm{~g}$, which is more than twice as high as in the barrier impact.

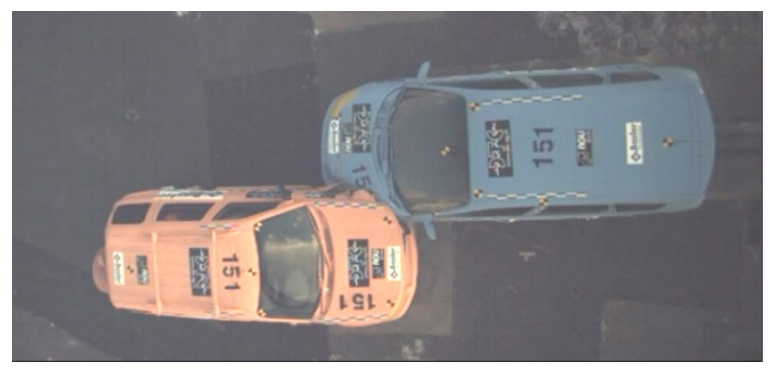

Figure 19. The longitudinal bars do not participate 
Nevertheless up to this point neither belt tensioners nor airbags were deployed (Fig. 19). The battery ejected by the deformation of the front structure and separated from the vehicle.

The closer the two passenger compartments came, the stronger they started to slip off. At the moment of the mutual contact of the passenger compartments, the belt tensioners and airbags of both vehicles were deployed (Fig. 20). The left front wheels of both vehicles are demolished and pushed against the driver side foot well.

The collision-induced change in velocity in the x-direction was for the Scénic $38.1 \mathrm{~km} / \mathrm{h}$ (Fig. 21) and for the Freelander $27.1 \mathrm{~km} / \mathrm{h}$ (Fig. 22). the Renault Scénic II separated from the Land Rover Freelander with $66.7 \mathrm{~km} / \mathrm{h}$ (Fig. 21). The Scénic started to swerve due to the momentum of the collision and the lacerated left front wheel. If there were a secondary collision in this situation, the frontal passive safety devices such as belt tensioners and airbags would already have been triggered. In addition there are vehicles on the market where the function of the airbag control unit is not ensured long enough with disconnected battery. If there were a secondary side collision, the ignition of the side airbags must be guaranteed at the very least.

In the release phase of the two vehicles after slipping off, the Renault Scénic II rotated significantly less around the z-axis than in crash DTC 150 (Fig. 23).

The loads measured on the ATD (Fig. 24) were well below the biomechanical limits according to ECE-R 94 (frontal crash).[4]

The driver foot well of the vehicle was slightly indented. On the instrument panel is shown a mark of the left ATD leg (Fig. 25). The legs of the ATD were not trapped. The dummy head was well supported by the airbag (Fig. 26) in spite of vehicle rotation around the z-axis and the lateral displacement due to the slipping off. The belt tensioner and the airbag could exert their protective effects very well.

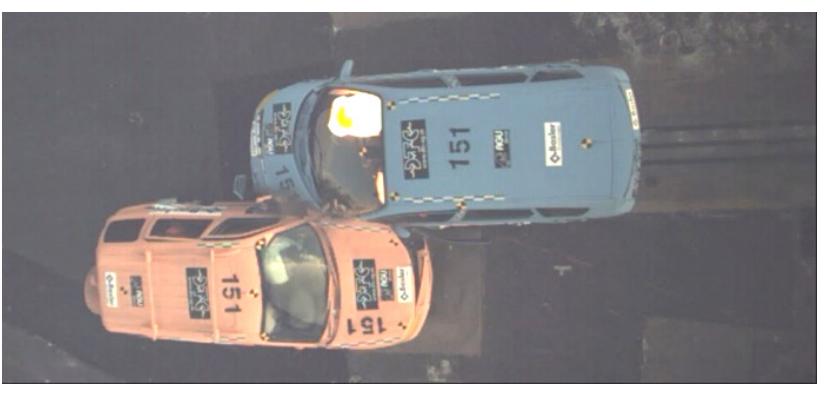

Figure 20. The vehicles slip off each other

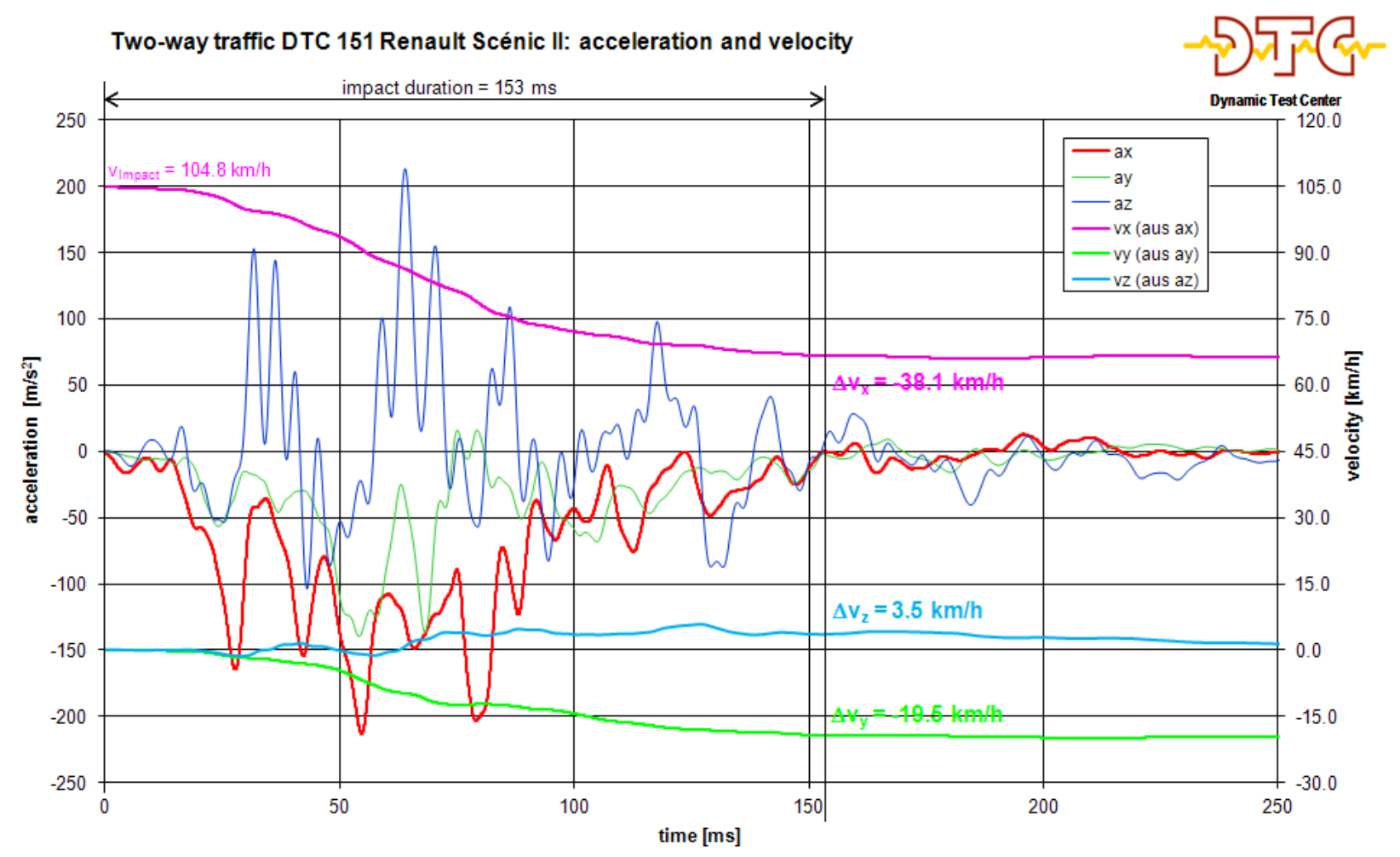

Figure 21. Vehicle loads Renault Scénic II 
Two-way traffic DTC 151 Landrover Freelander: acceleration and velocity

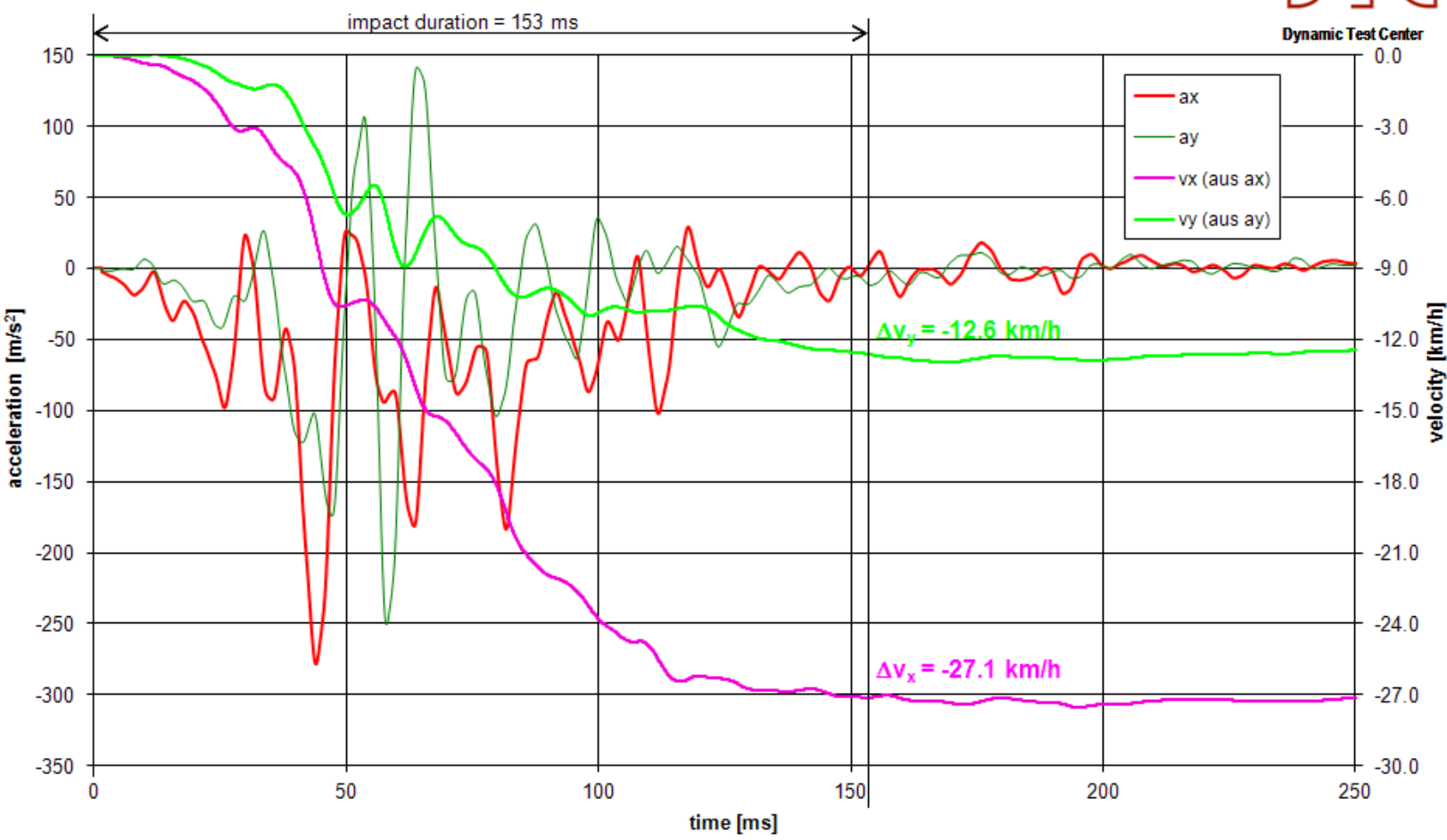

Figure 22. Vehicle loads Land Rover Freelander

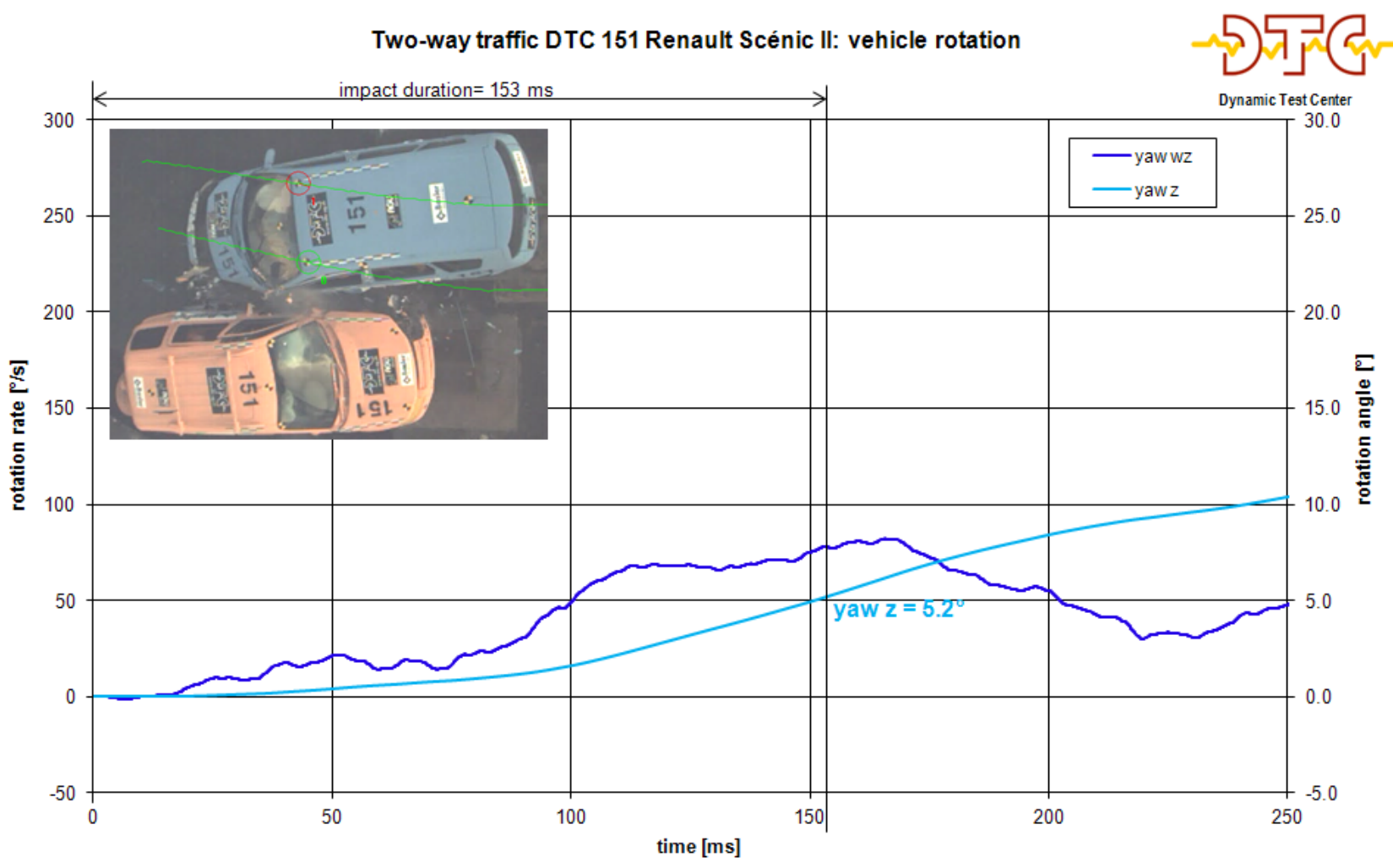

Figure 23. Vehicle rotation of Renault Scénic II 


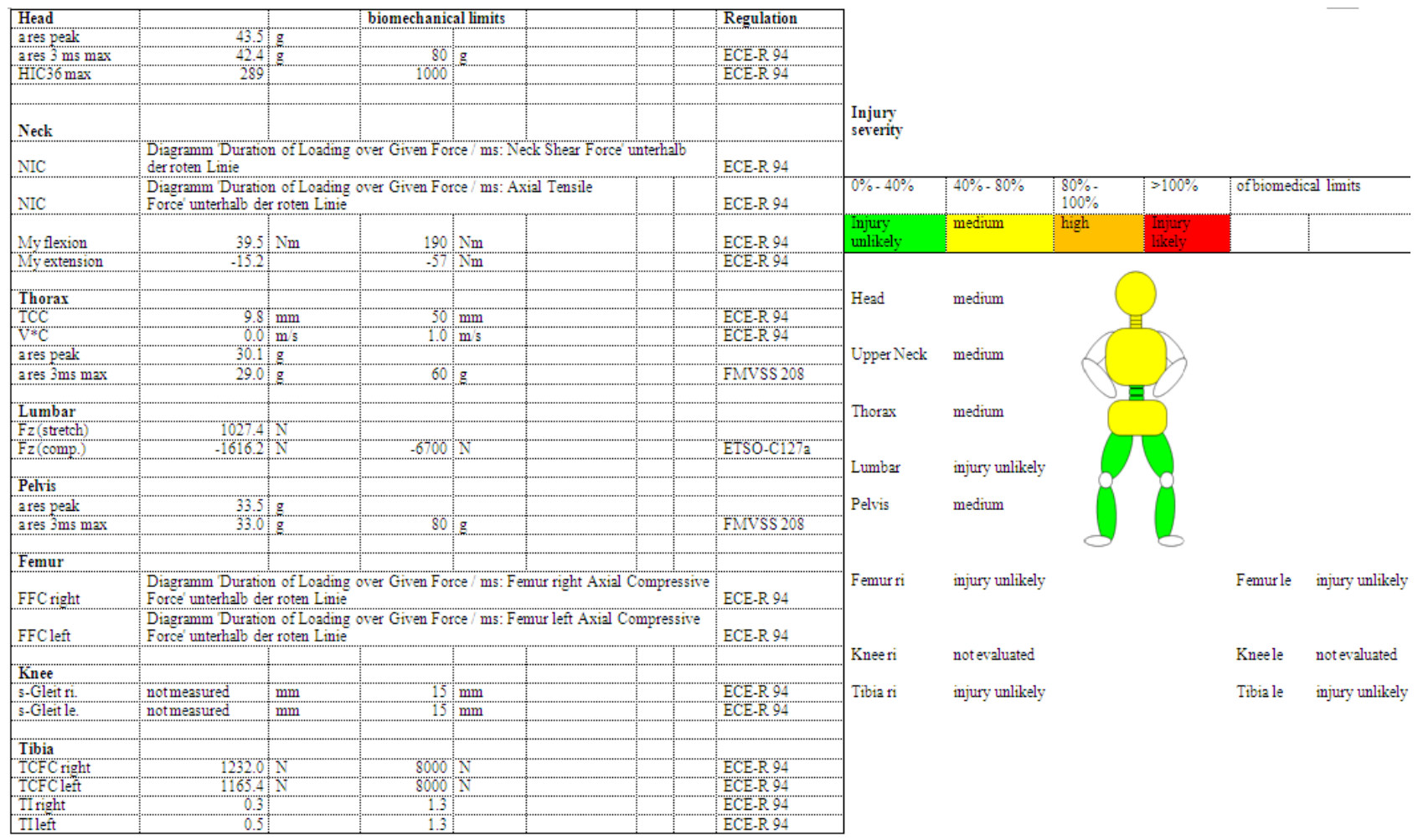

Figure 24. Loads on driver ATD, Renault Scénic II

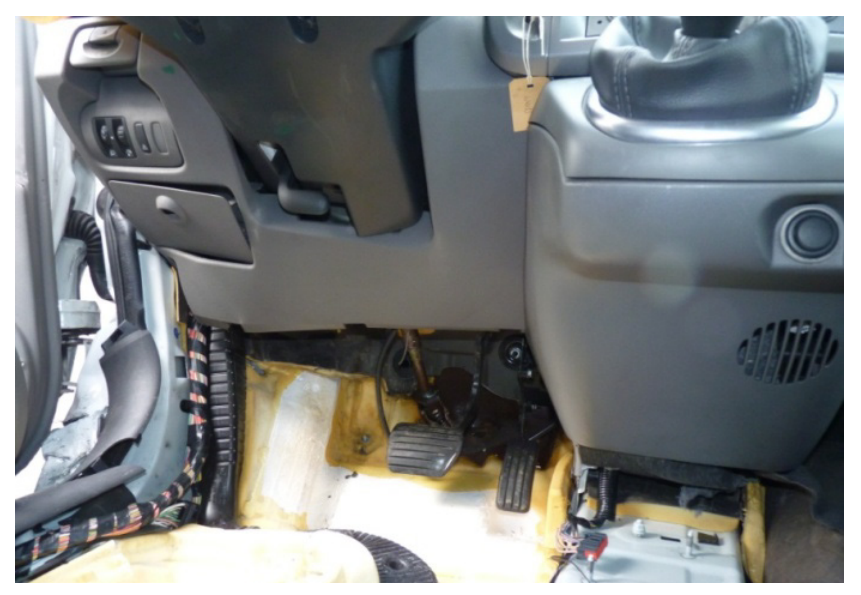

Figure 25. Driver foot well

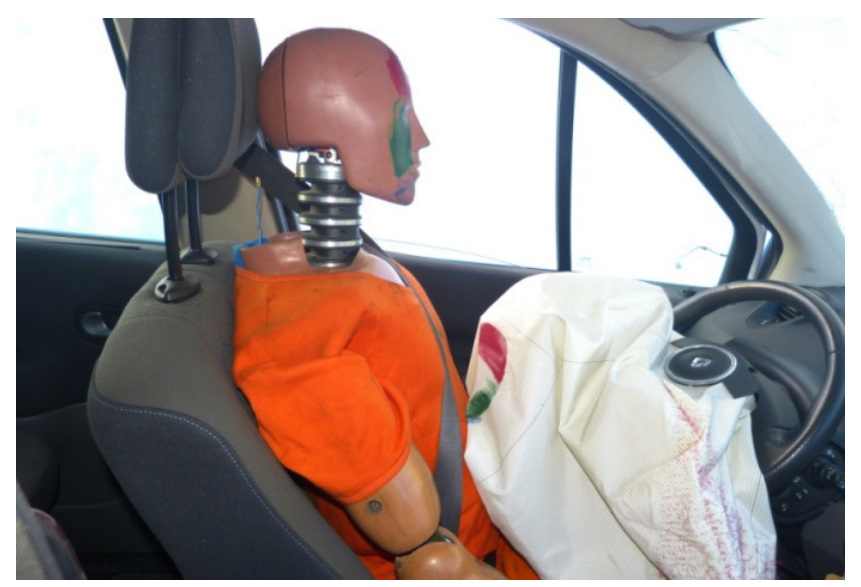

Figure 26. Dummy head marks on the airbag 


\subsection{DTC 149 Renault ScÉNic, IIHS with Reduced Velocity}

The vehicle hits the IIHS small overlap barrier with $46.7 \mathrm{~km} / \mathrm{h}$ and an overlap of $25 \%$ (Fig. 27). The Renault Scénic II grazed with the left longitudinal bar along the barrier. The longitudinal deceleration during the first $40 \mathrm{~ms}$ was $2.5 \mathrm{~g}$ on average.

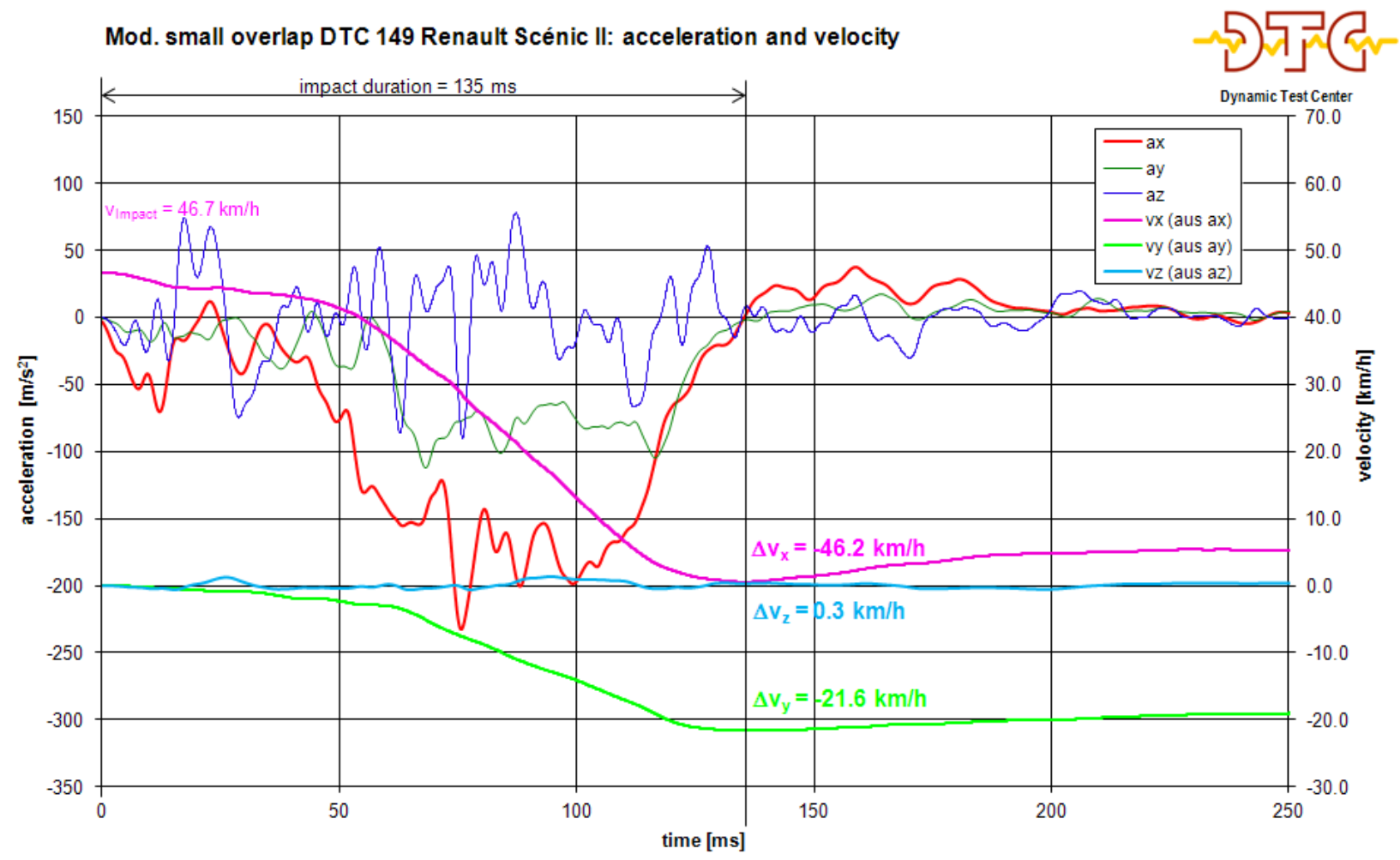

Figure 27. Vehicle loads

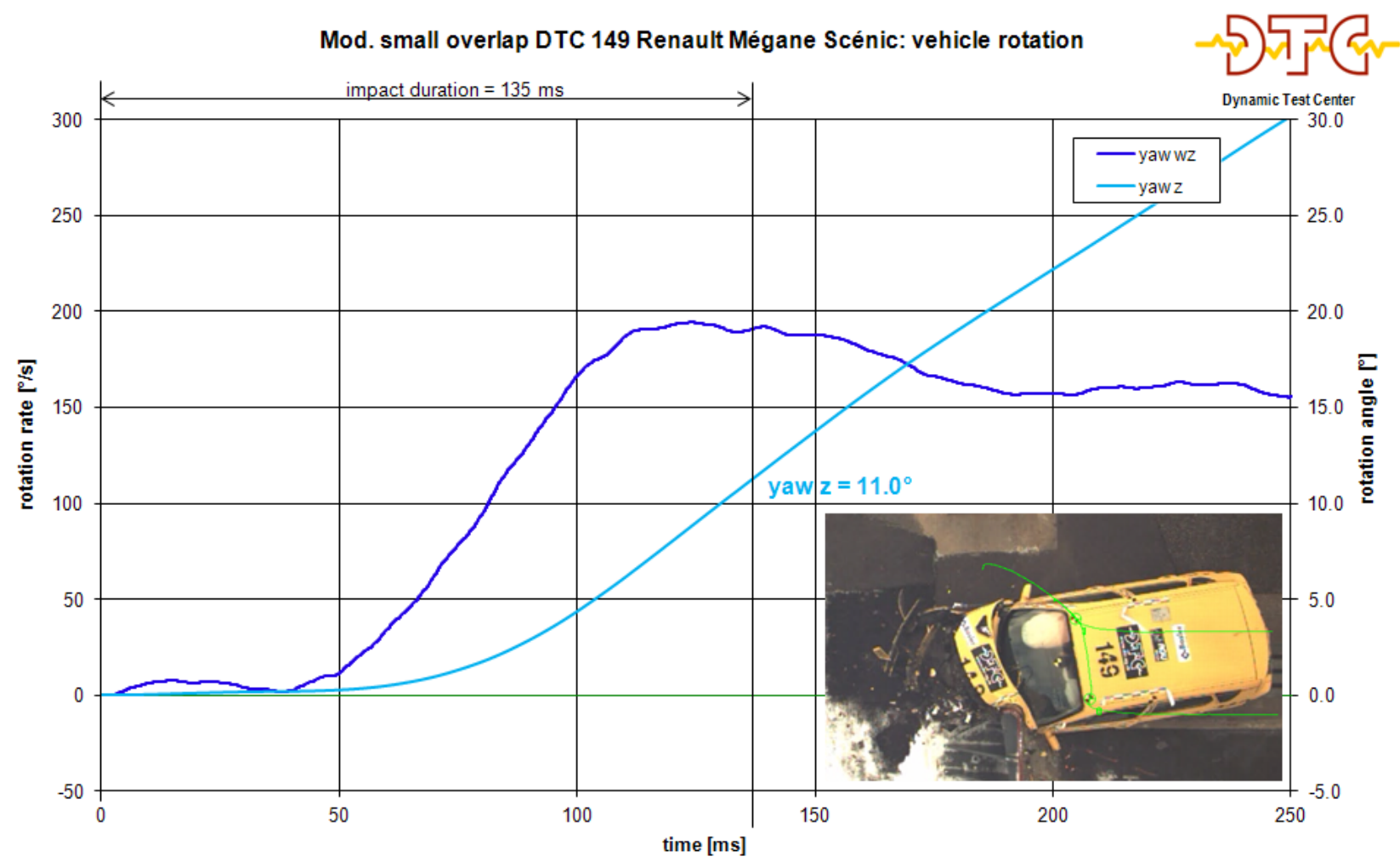

Figure 28. Vehicle rotation 
The rotation rate was quite on same level as on the test with the higher impact velocity DTC 150 (Fig. 15 and 28).

Neither the belt tensioners nor the airbags were deployed at this low level of deceleration (Fig. 29). The battery was ejected by the deformation of the front structure and separated from the vehicle.

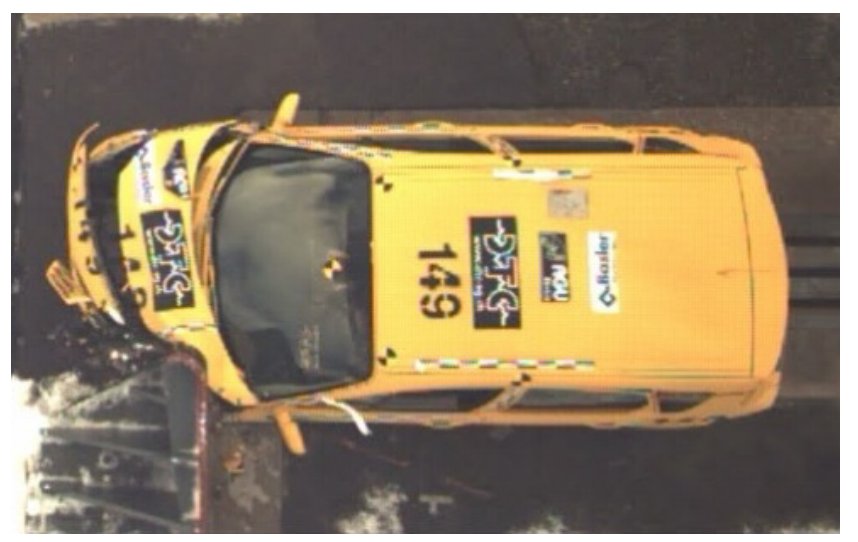

Figure 29. The longitudinal bar slides past the barrier

The car did not slip off. The left front wheel was pressed into the driver foot well and the passenger compartment has blocked on the IIHS small overlap barrier. The belt tensioners and airbags were deployed (Fig. 30). By the acting rotation of the vehicle around the z-axis, caused by the collision, the movement of the ATD turns to the vehicle outside (Fig. 33). The vehicle rotated more than $60^{\circ}$ and stopped three feet away from the barrier.

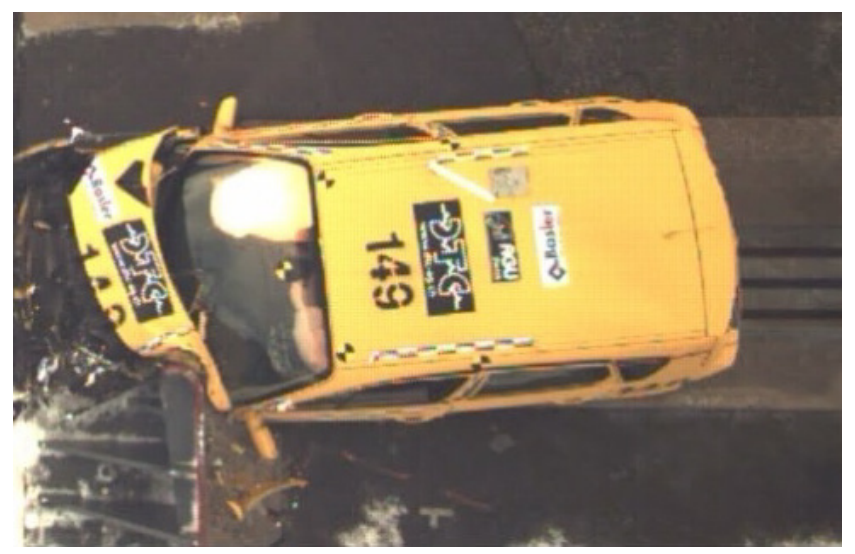

Figure 30. Blocking of the compartment with the barrier

The passenger compartment has well resisted the impact on the rigid barrier (Fig. 30). The deformation of the driver door shows that the limit of the energy input in the structure of the vehicle was reached at the low overlap of $25 \%$. Because the longitudinal bar slid past the IIHS small overlap barrier, the defined deformation zone was almost ineffective. The energy of the impact could due to the two-way collision against the Land Rover Freelander matched impact speed of $46 \mathrm{~km} / \mathrm{h}$ be absorbed through the front outer structure, the left suspension and mainly by the blocking of the passenger compartment. Thereby the passenger compartment remained mainly intact.

Marks of the ATD legs are shown on the instrument panel (Fig. 32). The dummy legs were not trapped. The loads measured on the ATD (Fig. 31) were well below the biomechanical limits according to ECE-R 94 (frontal crash).[4] 


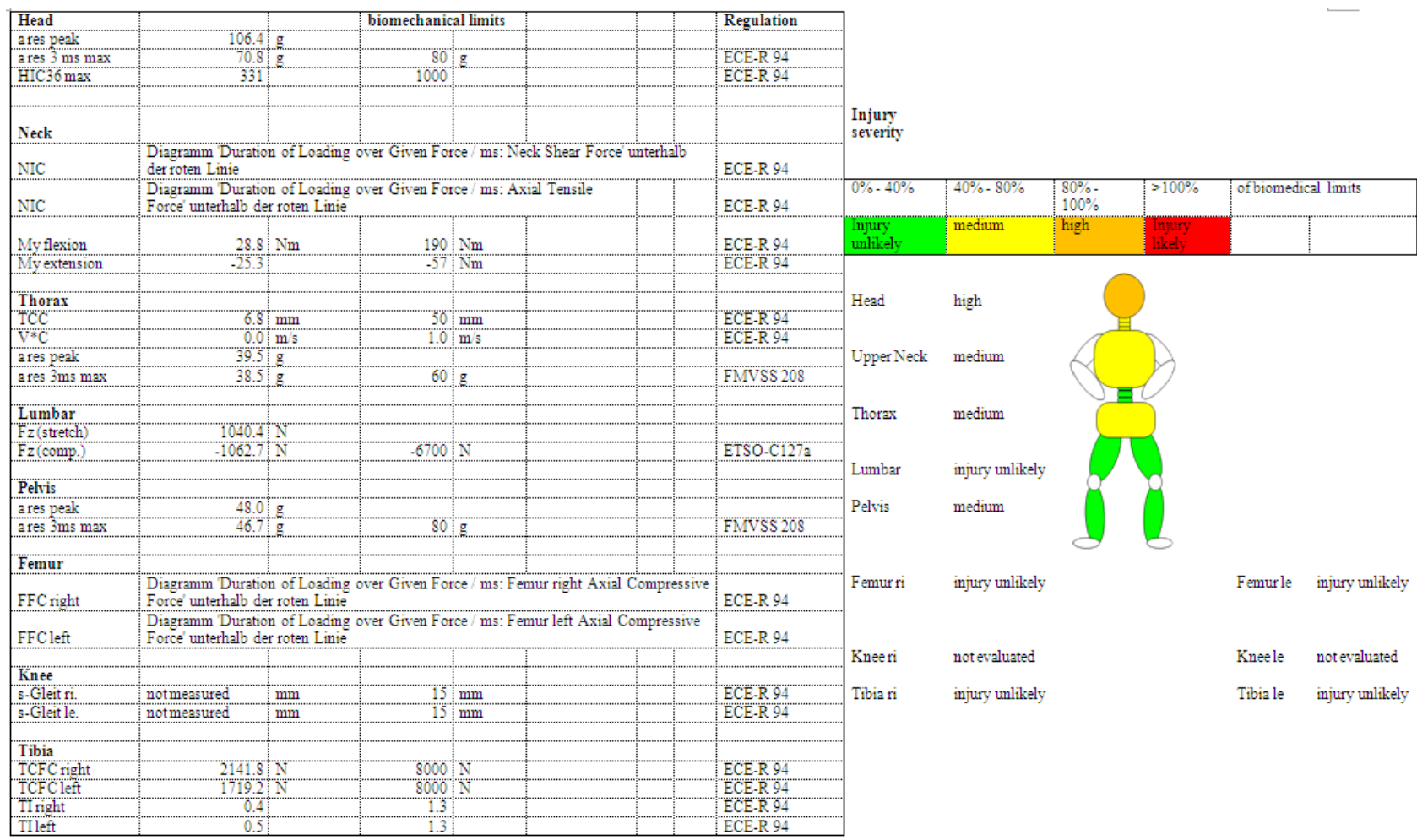

Figure 31. Loads on driver ATD

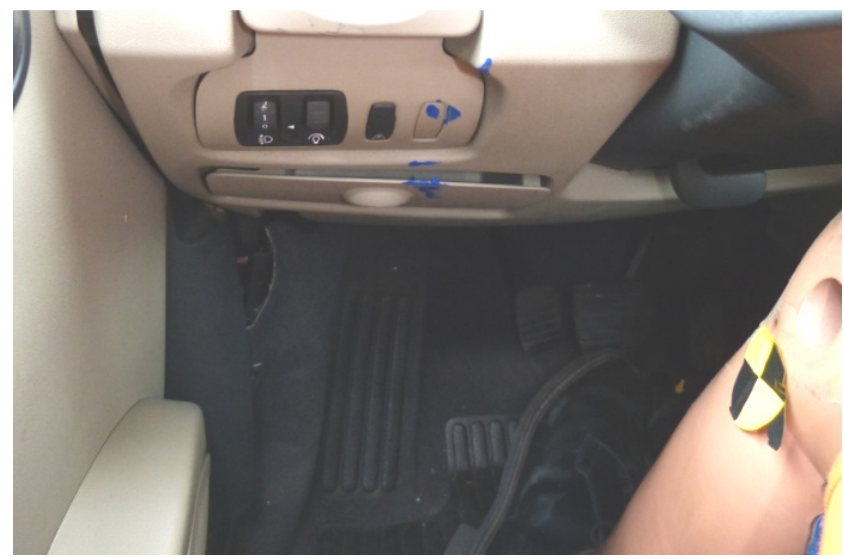

Figure 32. Reduced driver foot well

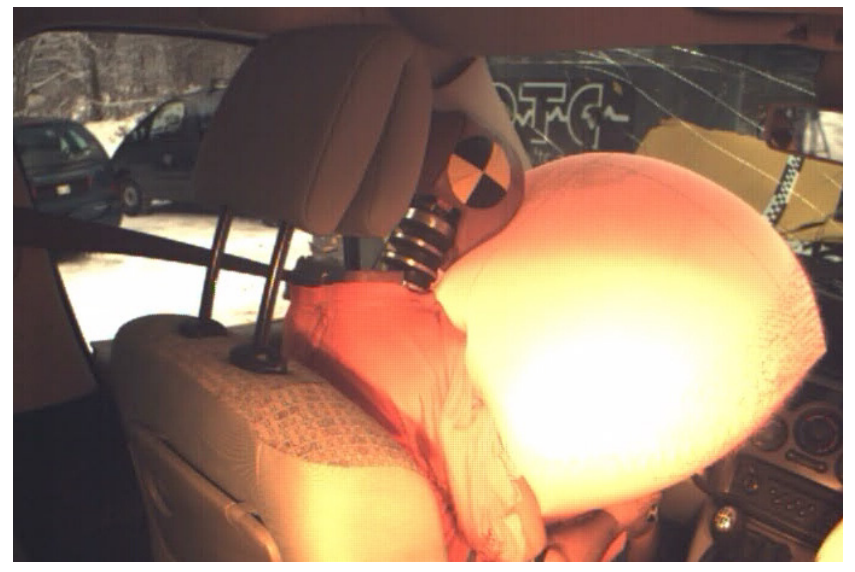

Figure 33. Dummy head on the airbag 


\subsection{DTC 152 Ford Mondeo Modified, Test According to IIHS}

With the example of a Ford Mondeo was examined how the occupant loads develop if the vehicle was designed to slip off the barrier.

The vehicle impacts with $65.2 \mathrm{~km} / \mathrm{h}$ and an overlap of $25 \%$ on the IIHS small overlap barrier. First, the vehicle glided along the barrier with the left longitudinal bar to the extra fitted profile (Fig. 34). Thereby much more energy was absorbed than in the tests DTC 149 and 150. With the modified structure, the vehicle started to slip off the IIHS small overlap barrier and the front wheel was pressed inwards. The restraint systems such as airbags and belt tensioners were triggered.

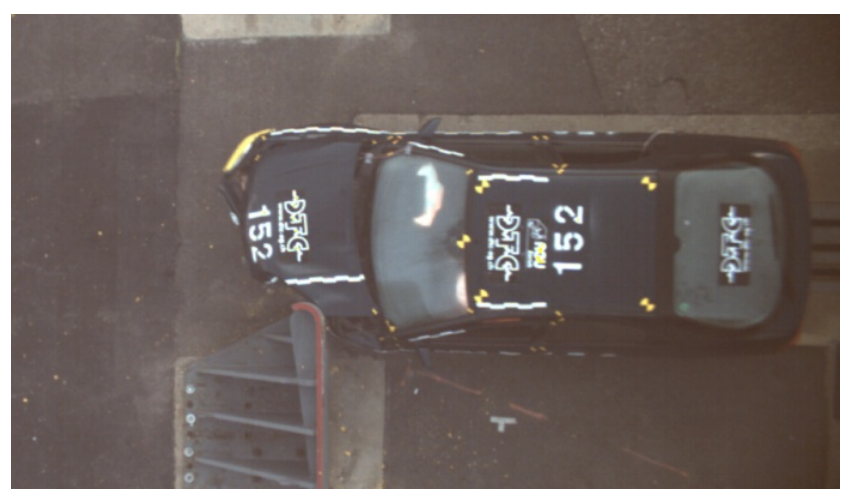

Figure 34. The front structure is pushed away from the barrier

The passenger compartment deformed only slightly because the vehicle was forced to slip off the barrier (Fig. 36). This can be traced back to the old model year.

The ATD moves in consequence of the vehicle movement obliquely forward to the outside.

Due to the slip off the remained speed was $30 \mathrm{~km} / \mathrm{h}$ after the collision (Fig. 35).

Due to the vehicle slipping off the IIHS small overlap barrier the passenger compartment remained largely intact. Furthermore the left front wheel was prevented from being hooked and torn off (Fig. 39). The rotation rate around the z-axe was first low and changed then the direction (Fig. 37). It should be noted that the structure of the vehicle is not designed for the Euro-NCAP due to its old model age (compare Fig 8 to 10).

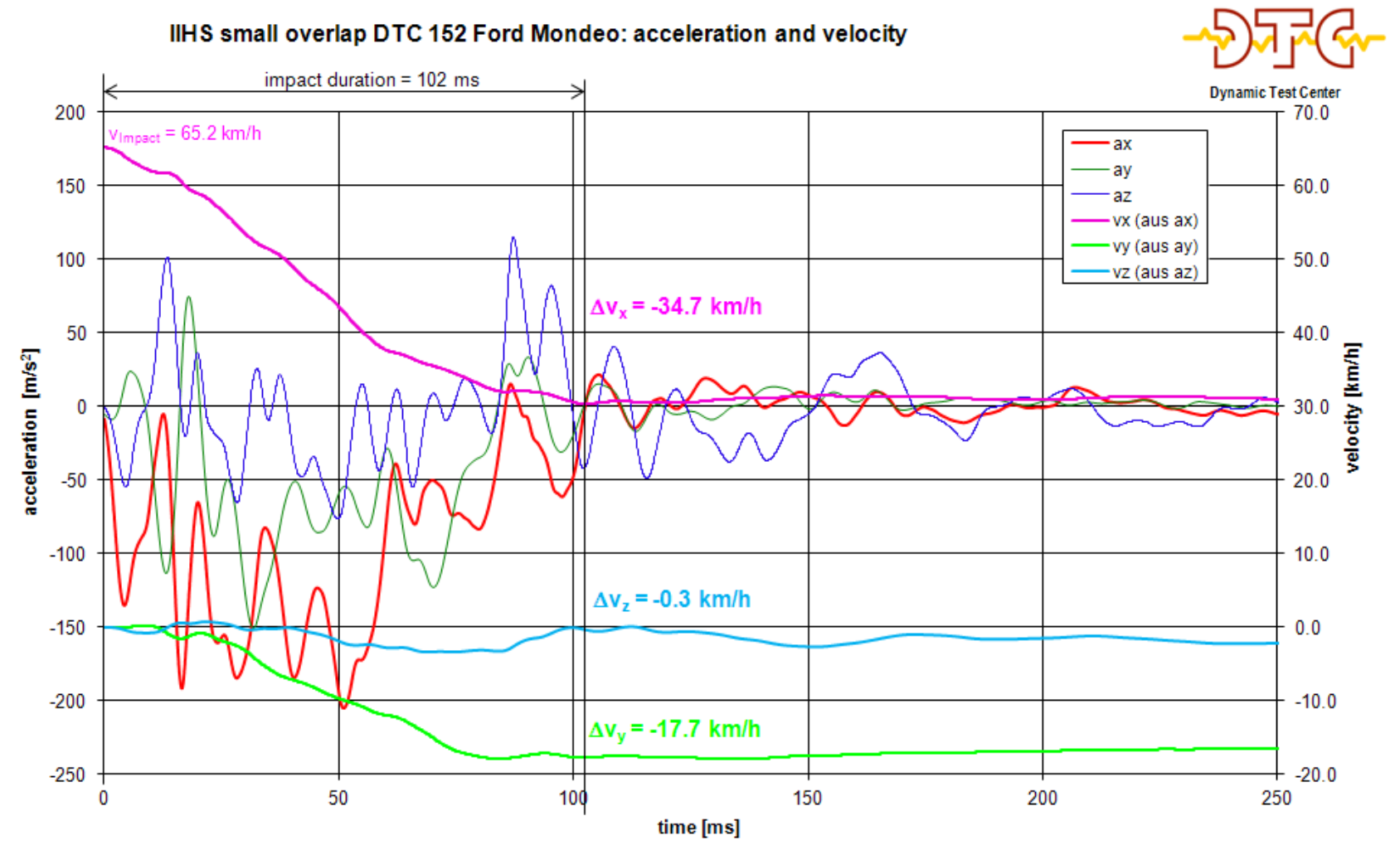

Figure 35. Vehicle loads 


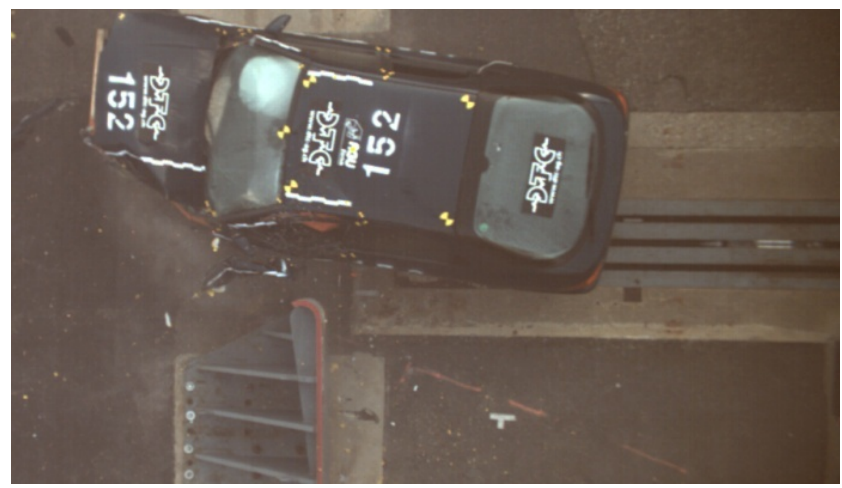

Figure 36. Different slip off kinematics

IIHS small overlap DTC 152 Ford Mondeo: vehicle rotation

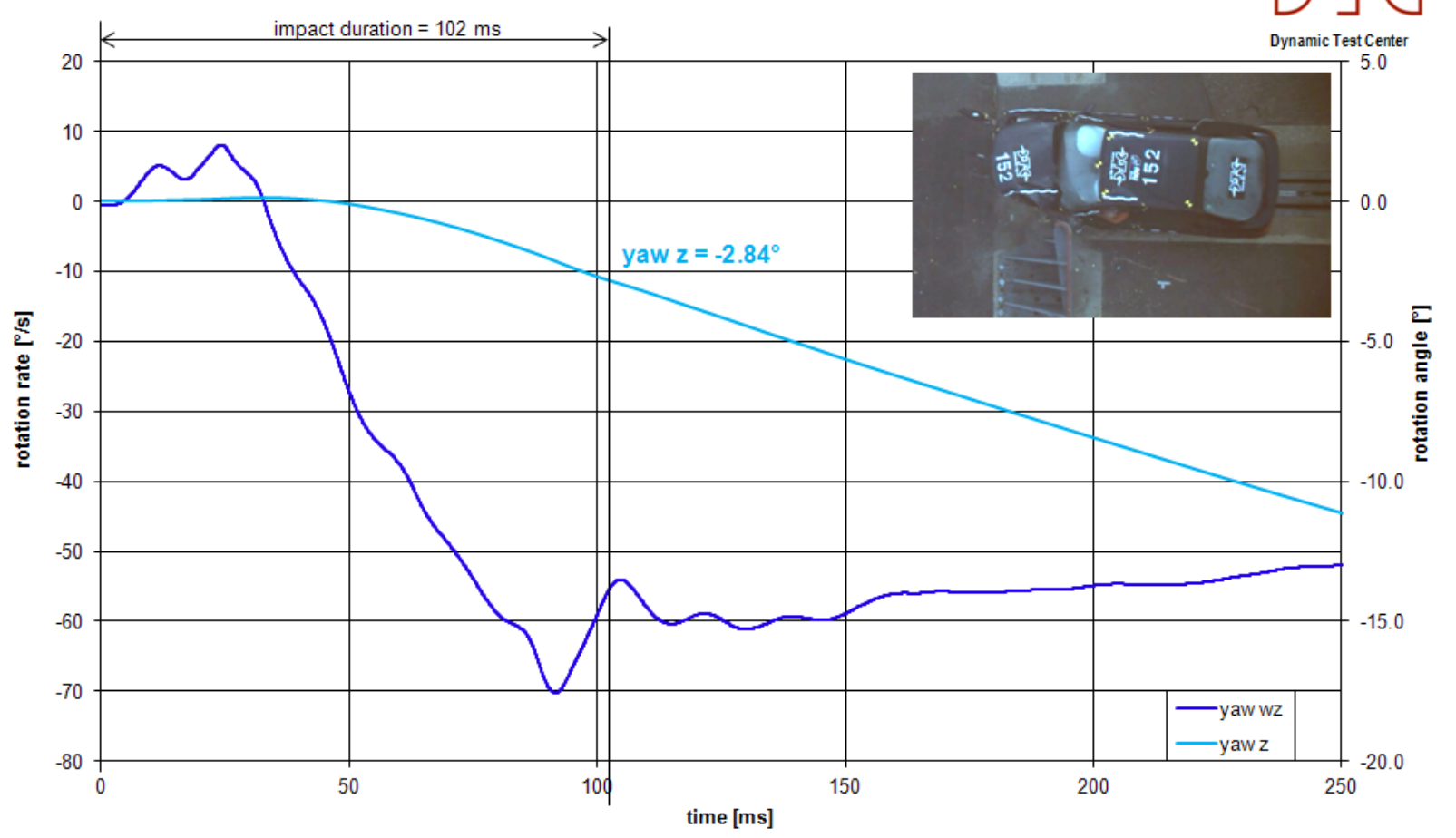

Figure 37. Vehicle rotation 


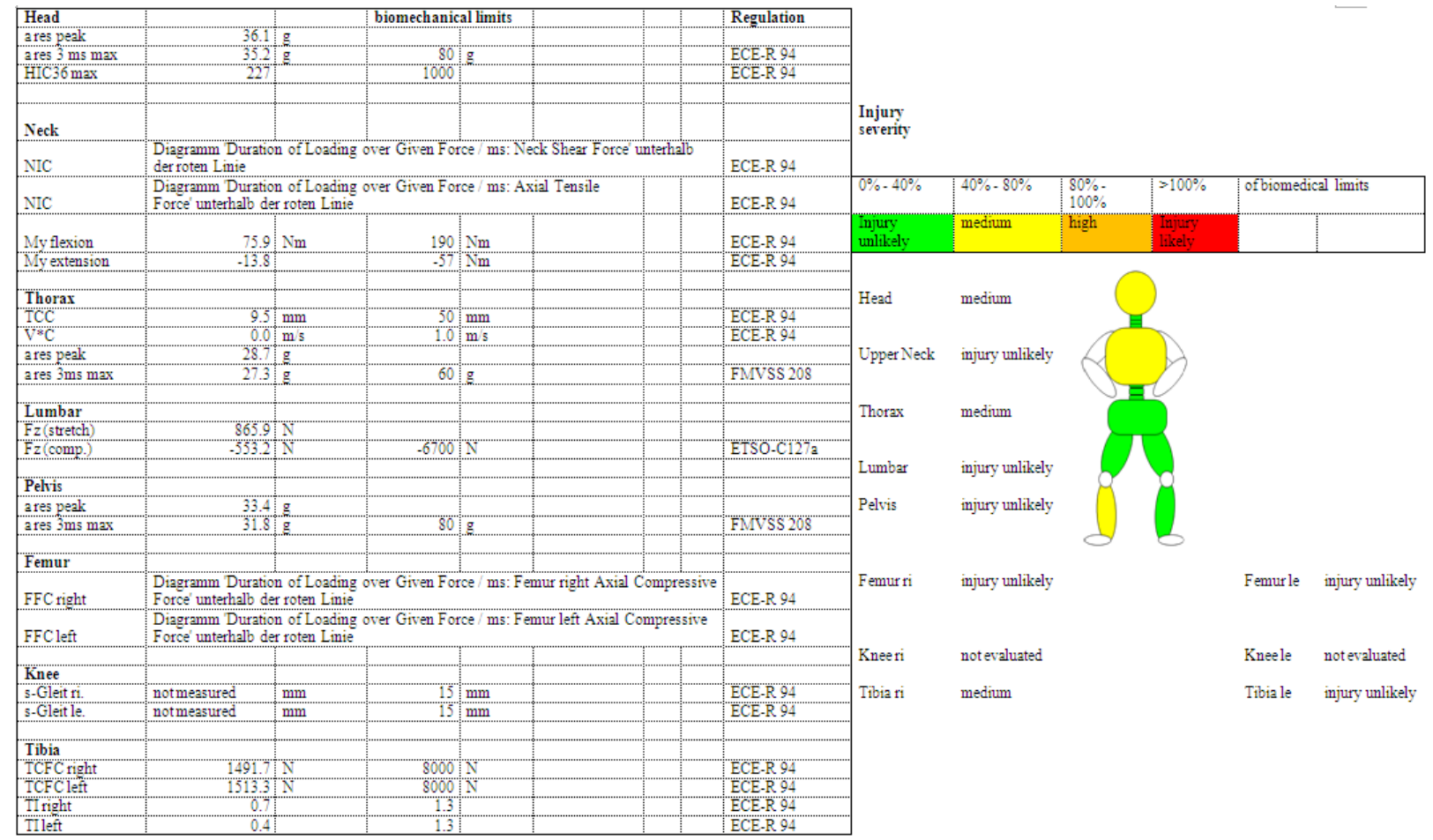

Figure 38. Loads on driver ATD

The ATD did not hit the front airbag due to its transverse movement and the lateral movement of the vehicle (Fig. 40). The vehicle used was equipped with first-generation airbags without side airbags. The measured ATD loads (Fig. 38) were compared to the previous crash tests generally the lowest and substantially below the biomechanical limits according to ECE-R 94 (frontal crash).[4]

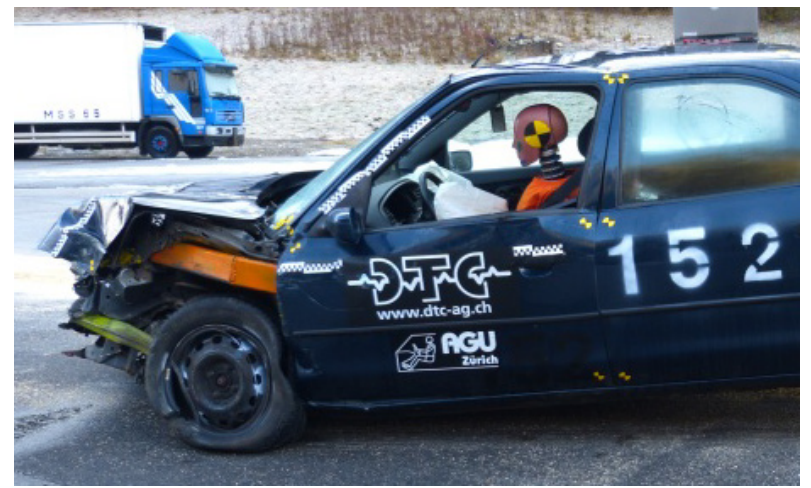

Figure 39. Largely intact passenger compartment and foot well

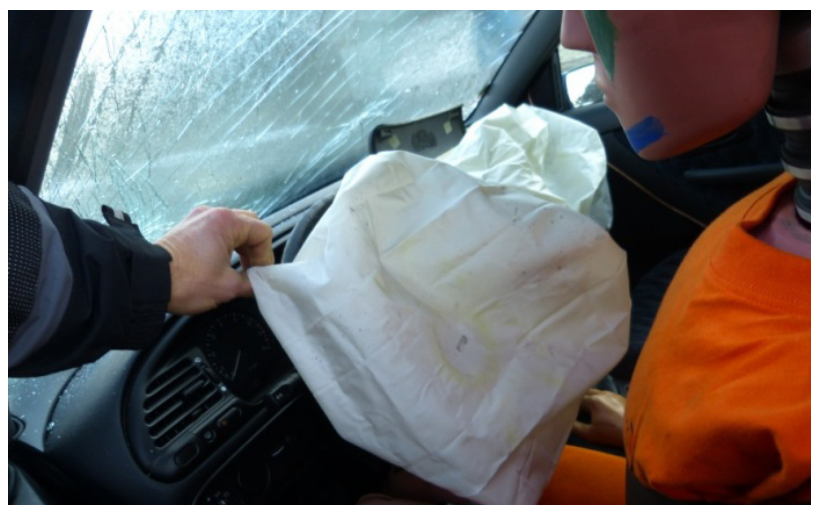

Figure 40. The front airbag was missed 


\section{Interpretation and Analysis}

\subsection{IIHS Small Overlap Crash (DTC 150) in Comparison With the Two-way Traffic Collision (DTC 151)}

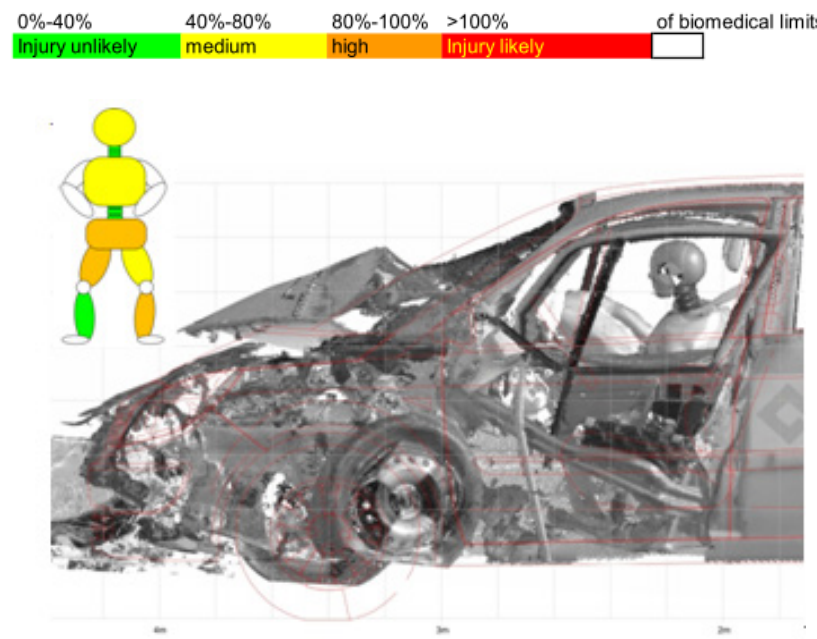

Figure 41. Passenger compartment after IIHS small overlap Crash DTC 150

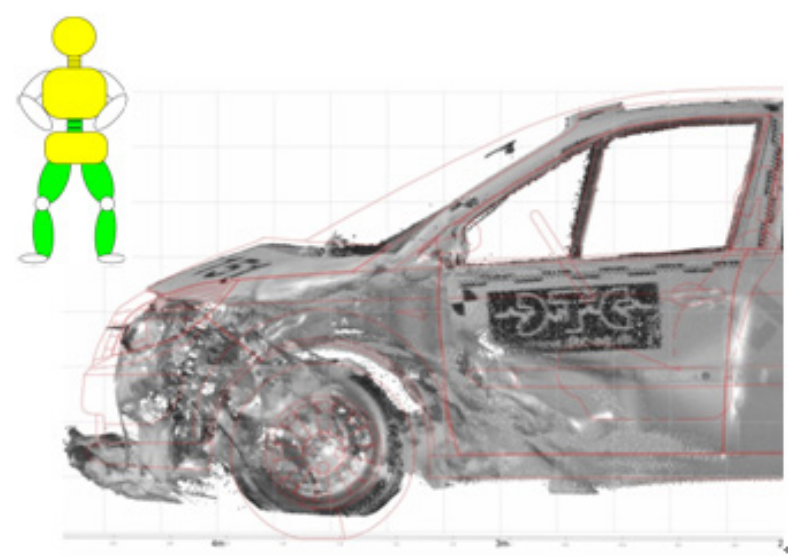

Figure 42. Passenger compartment after two-way traffic collision DTC 151

The left longitudinal bars of the vehicles could not be supported in both types of collisions due to the small overlap of $25 \%$, and were therefore not involved in the energy absorption. The upper longitudinal bar below the fender of the Renault Scénic II is barely deformed. A hard impact on the passenger compartment at the bottom of the A-pillar was not observed in the two-way traffic collision. Nevertheless, the impact energy, until the passenger compartment was involved respectively until the slip off, could be reduced so that the survival space for the occupants remained largely intact. In tendency the structural loads from the two-way traffic collision (DTC 151) are comparable with those from the small overlap IIHS crash test (DTC 150) at $64 \mathrm{~km} / \mathrm{h}$. The deformations and the occupant loads in the two-way traffic collision (DTC 151) were significantly lower at the pelvis and lower extremities than the impact on the rigid barrier because of the slip off and the thereby missing impact of the passenger compartment on the Land Rover Freelander, (Fig. 41 and 42).

The impact speed of IIHS small overlap crash test against the rigid barrier is settled too high in comparison with the two-way traffic collision between a Renault Scénic II and a Land Rover Freelander.

\subsection{IIHS Small Overlap Crash with Reduced Velocity (DTC 149) in Comparison With the Two-way Traffic Collision (DTC 151)}

The Renault Scénic II hooked to the barrier at the IIHS small overlap crash test with reduced velocity. The left longitudinal bar was not hit by the rigid barrier. The upper longitudinal bar underneath the fender was in contrast to the oncoming traffic collision (DTC 151) with the Land Rover Freelander completely deformed. The impact energy could be mainly absorbed up to the passenger compartment despite the small overlap, so that the survival space for the occupant is still largely intact. The driver side foot well was similar to the two-way traffic collision (DTC 151) slightly deformed by the torn off wheel.

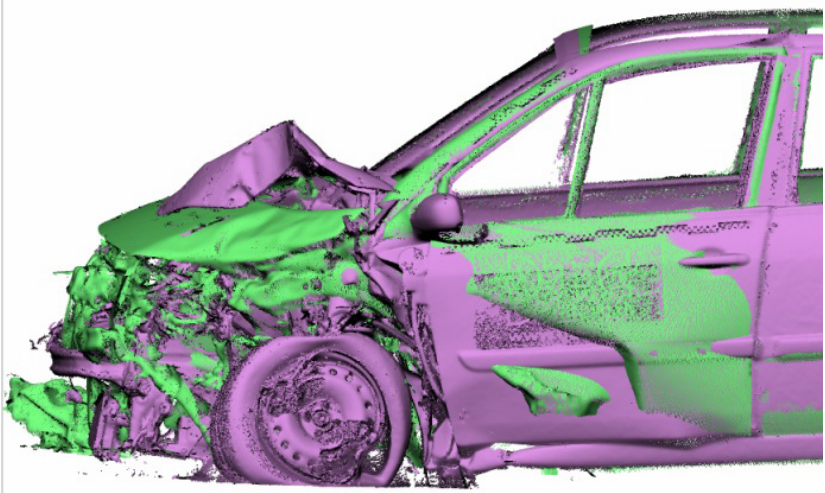

Figure 43. Overlay of both vehicle deformations IIHS Barrier DTC 149 (violet) and two-way traffic DTC 151 (green)

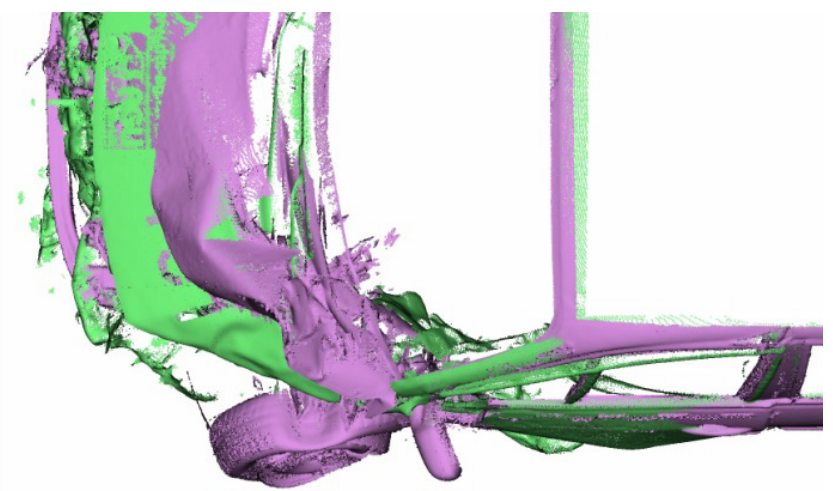

Figure 44. View from the top

The measured pressure in the left leg of the ATD was slightly higher than in the right leg. The measured loads were in both tests well below the biomechanical limits (Fig 
42 and 43) according to ECE-R 94 (frontal crash).[4] Only the $3 \mathrm{~ms}$ head acceleration was slightly higher compared to the oncoming traffic collision. This could be substinated by higher collision induced velocity change on one hand, and, on the other hand by the higher rotation of the vehicle about the z-axis (DTC 149: 11.0 / DTC 151: 5.2 ${ }^{\circ}$ ) and thus an unfavorable support of the head to the front airbag.

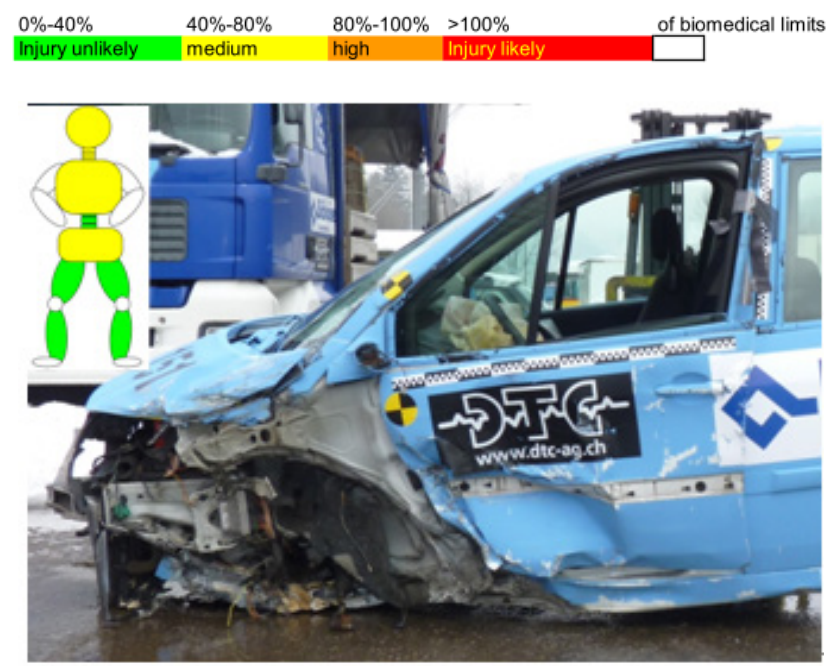

Figure 45. Passenger compartment after two-way traffic collision DTC 151

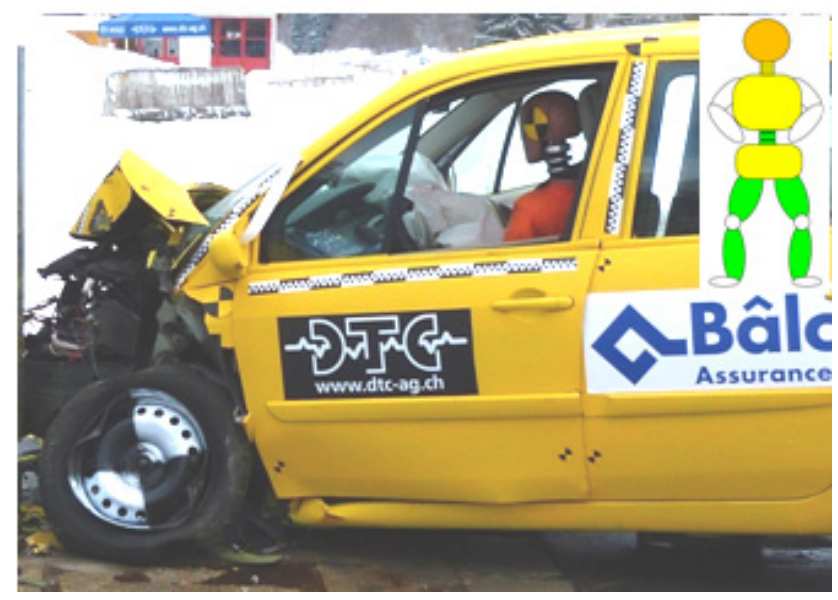

Figure 46. Passenger compartment after IIHS small overlap Crash with reduced velocity DTC 149

The crash test DTC 149 has shown that the structure- and occupant loads of the two-way traffic collision between the Renault Scénic II and a Land Rover can be simulated on the IIHS rigid barrier. The impact velocity had to be reduced to $46 \mathrm{~km} / \mathrm{h}$ for the Renault Scénic II.

\subsection{Slip off (DTC 152) in Comparison of the Energy Absorption on the Rigid Barrier (DTC 149 \& DTC 150)}

The Ford Mondeo has slipped off the IIHS small overlap barrier after the deformation of the front structure because of the additionally implemented structure parts. A hard impact on the passenger compartment at the bottom of the A-pillar was not observed so that the survival space for the occupants remained largely intact. Airbag and belt tensioners were triggered. The restraint systems could develop their protective effect only conditionally. The driver dummy missed the front airbag due to its inertia caused by the abrupt slip off and the resulting lateral movement of the vehicle. But thanks to the belt retention the head did not hit the instrument panel or the vehicle structure. The Ford Mondeo has much narrower space in the foot well in comparison with the Renault Scénic II. Therefore slightly increased loads were measured on the legs of the ATD. The measured loads were all over the Body the lowest and well below the biomechanical limits according to ECE-R 94 (frontal crash).[4]

The deformations and the occupant loads in the collision were because of the slip off and the thereby missing impact of the passenger compartment on the small overlap barrier significantly lower than in the crash tests DTC 149 and DTC 150 (Fig. 47, 48 and 49), at which the vehicles have hooked into the IIHS small overlap barrier.

\begin{tabular}{|c|c|c|c|c|}
\hline $0 \%-40 \%$ & $40 \%-80 \%$ & $80 \%-100 \%$ & $>100 \%$ & of biomedical limits \\
\hline Injury unlikely & medium & high & Injury likely & \\
\hline
\end{tabular}

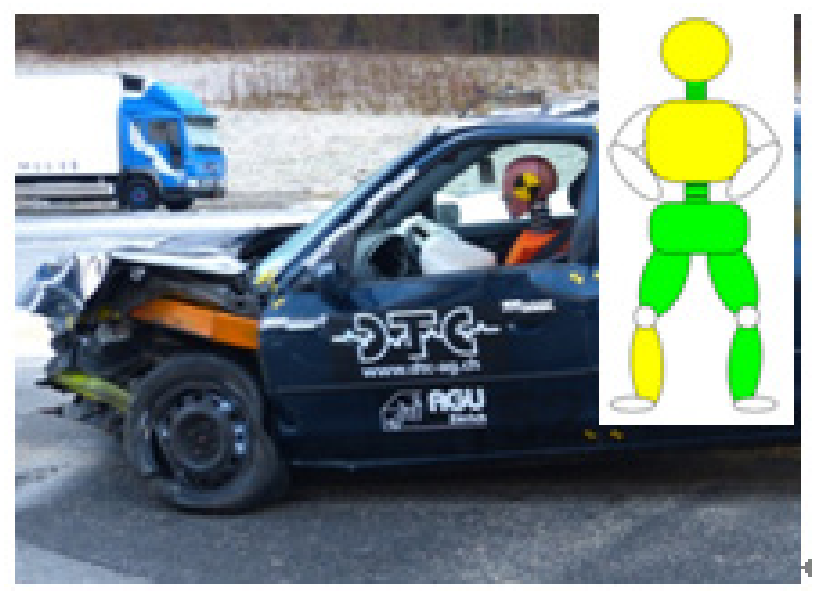

Figure 47. Driver compartment after IIHS small overlap crash with slip off DTC 152

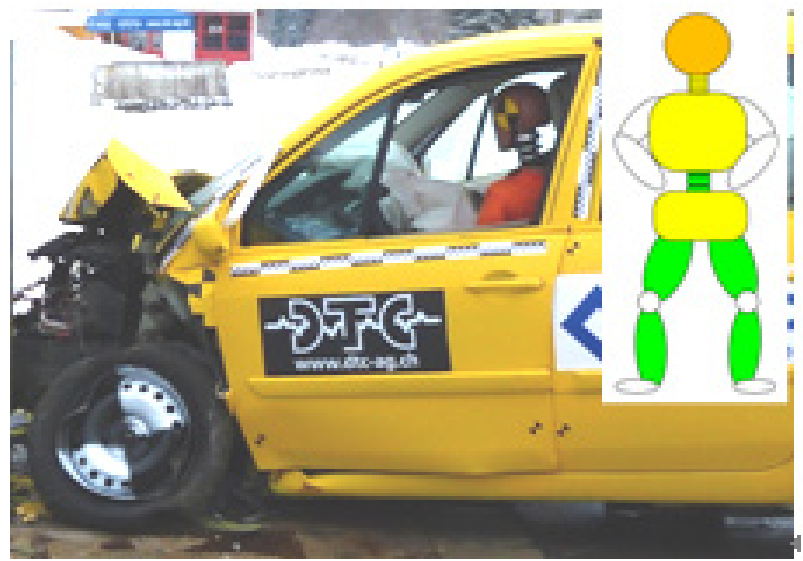

Figure 48. Driver compartment after IIHS small overlap crash with reduced velocity DTC 149 


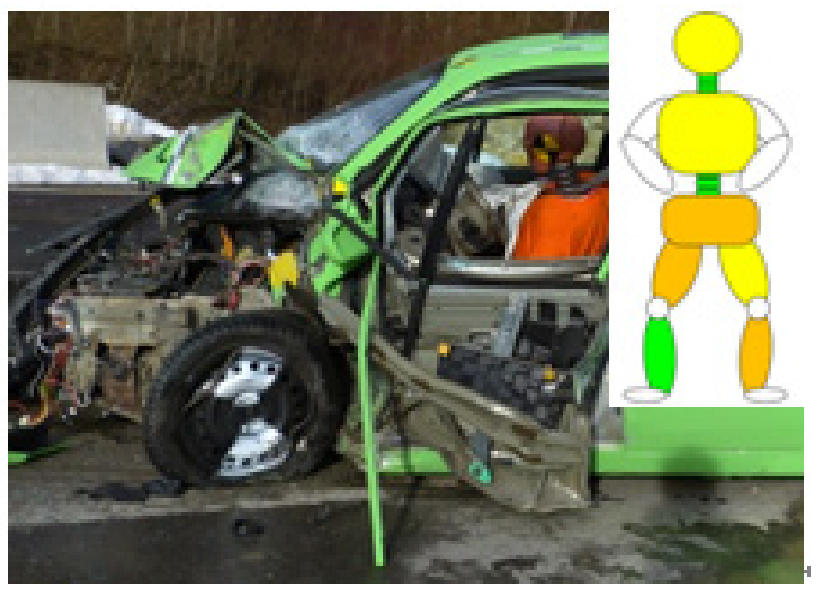

Figure 49. Driver compartment after IIHS small overlap crash DTC 150

The modified Ford Mondeo has shown a similar behaviour by the slip off on the IIHS barrier as in collision tests with safety barriers and crash cushions. This specific analysis showed the following results: [5]

While the specified limits for safety barrier tests are significantly exceeded at hooking with the rigid barrier (DTC 150), they can be observed by slipping off (DTC 152).

How the constructive measures, which enable a slip off on the small overlap crash test can be integrated into the front structure has to be determined type-specific by the vehicle manufacturers. It must be ensured that the structural adaptations do not have adverse effects on other accident scenarios. The front airbag is no longer hit optimal due to the lateral movement of the vehicle. Side airbags as first protective measure would be more effectively. A contact with the instrument panel and the A-pillar has certainly to be prevented by a corresponding airbag.

The vehicle still has kinetic energy after the primary impact and skids possibly further on the roadway. The already activated passive safety features would be exhausted and no more or only insufficiently available if a second collision occurs. Reusable tensioners and airbags could solve the problem. The tests have shown that the vehicle battery could be separated already very early during the crash. Without battery current airbag control units are only a very short time active. Although the right side airbag would be still applicable, it must be ensured that safety systems could still be released in a second collision seconds after the primary impact.

The vehicle brake should respond automatically and the vehicle brought as quickly as possible to a standstill because it cannot be steered in all probability (VW Golf VII multi collision brake [7] ).

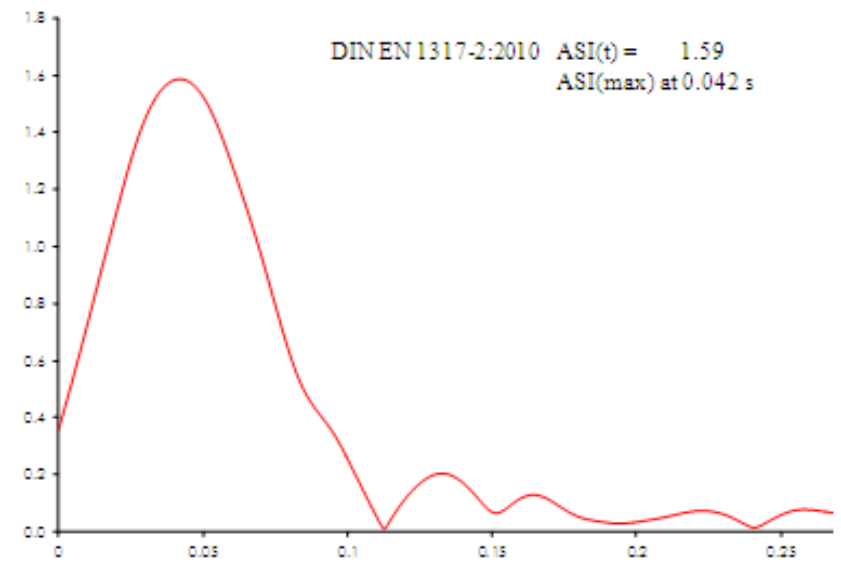

Figure 50. ASI evaluation DTC 152

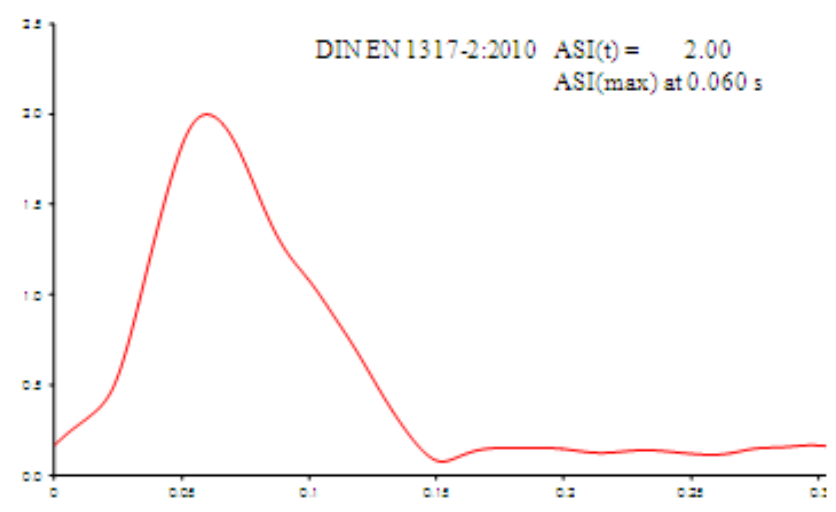

Figure 51. ASI evaluation DTC 150 


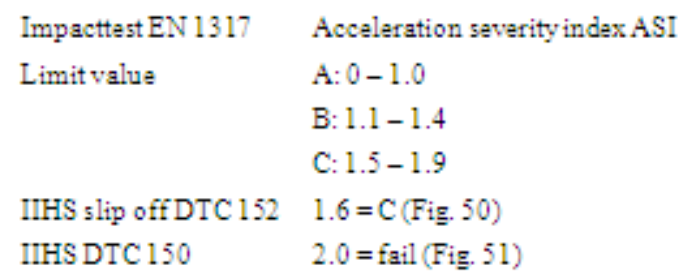

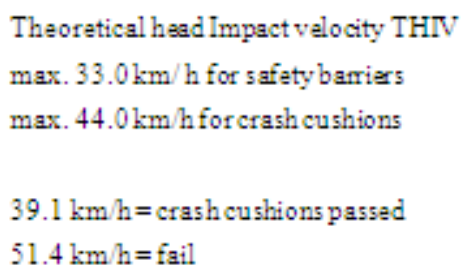

\section{Conclusion}

The studies clearly show that the small overlap crash test reveals some gaps in the design of passive safety concepts of modern vehicles. The actual number of accidents, accident images and victims substantiate the relevance of such an impact constellation. The tests carried out have shown that two-way traffic collision between two vehicles can be reproduced accurately enough on the rigid IIHS barrier. The high settled collision velocity of the IIHS test is confirmed in a certain way by the real accidents. From the present perspective the strategy of slipping off seems to be target-aimed to handle a small overlap crash with such a high velocity on a rigid barrier, energetically and structurally uninfluenced and without affect the vehicle performance at other equally frequent types of collisions. The occupant protection could be extended to additional situations.

\section{Glossary}

A. AGU Working Group on Accident Mechanics

B. IIHS The Insurance Institute for Highway Safety IIHS

C. Euro-NCAP The official site of the European new car assessment programme -

D. DTC Dynamic Test Center AG

E. DTC XY Test number by the Dynamic Test Center $A G$
F. HIII 50\% A specific type of Dummy

G. ECE-R 94 Economic Commission for Europe, internationally agreed common technical requirements for motor vehicles, Occupant protection at frontal impact

H. Impacttest EN 1317 European standards for restraint systems on roads

I. ASI Acceleration severity index according to EN 1317

J. THIV Theoretical head Impact velocity according to EN 1317

K. ATD Anthropomorphic Test Device

\section{REFERENCES}

[1] Baloise Insurance, Aeschengraben 21, CH-4002 Basel

[2] Newspaper „20 min”, Tamedia Production Services, Werdstrasse 21, CH-8021 Zürich

[3] Small Overlap Frontal Crashworthiness Evaluation Crash Test Protocol (Version II)“, December 2012, from the Insurance Institute for Highway safety, IIHS

[4] ECE-R 94: Insassenschutz bei Frontalaufprall

[5] EN 1317: Rückhaltesysteme an Strassen

[6] SAFETY COMPANION 2013, carhs.training gmbh

[7] Volkswagen AG, Berliner Ring 2, 38440 Wolfsburg 